\title{
Anatomy, functional morphology, evolutionary ecology and systematics of the invasive gastropod Cipangopaludina japonica (Viviparidae: Bellamyinae)
}

\author{
Bert Van Bocxlaer ${ }^{1,2,3,4,5}$, Ellen E. Strong ${ }^{3}$ \\ ${ }^{1}$ Museum für Naturkunde, Leibniz Institute for Evolution and Biodiversity Science, Invalidenstraße 43, D-10115 \\ Berlin, Germany \\ ${ }^{2}$ Department of Animal Ecology and Systematics, Justus Liebig University, Heinrich-Buff-Ring 26-32 IFZ, \\ D-35392 Giessen, Germany \\ ${ }^{3}$ Department of Invertebrate Zoology, National Museum of Natural History, Smithsonian Institution, PO Box \\ 37012, MRC 163, Washington, DC 20013-7012 \\ ${ }^{4}$ Limnology Unit, Department of Biology, Ghent University, K.L. Ledeganckstraat 35, B-9000 Ghent, Belgium \\ ${ }^{5}$ E-mail: bert.vanbocxlaer@ugent.be
}

Key words: basal Architaenioglossa, Bellamya, fecundity, geometric morphometrics, histology, reproductive anatomy, sexual dimorphism

\begin{abstract}
The anatomy, functional morphology and evolutionary ecology of the Viviparidae, and the subfamily Bellamyinae in particular, are incompletely known. Partly as a result, genealogical relationships within the family remain poorly understood. Because of this lack in knowledge, few informed hypotheses exist on ancestral states, how differences in body plans between the subfamilies evolved, and how the peculiar biogeographic distribution patterns of viviparids have arisen. Here we document the anatomy, morphology, life history and systematics of Cipangopaludina japonica, a Japanese species that has been introduced into North America, to resolve taxonomic confusion and to improve our understanding of how form and function are related in bellamyines. Anatomical and histological examinations demonstrate marked differences between $C$.japonica and other bellamyines in the radula, salivary gland, kidney, nerve ring and reproductive organs. Substantial differences also exist between male and female body organization, but conchological differences between sexes in semi-landmark morphometric analyses are limited. The volume of the brood pouch of females, and hence body and shell size, appear to be good predictors of reproductive success, and the species' ecological versatility may relate to high fecundity and the ability to alternate between feeding modes. Comparing our observations on $C$. japonica with other viviparids and basal Architaenioglossa, we identify several persistent misinterpretations in the literature on how form and function are related in viviparids, not in the least as to female reproductive anatomy. Our reinterpretations improve understanding of the evolution of Viviparidae and its subfamilies, and hopefully will allow future workers to isolate key traits that shaped the evolution of viviparids at the taxonomic levels of their interest for more detailed studies.
\end{abstract}

\section{Contents}

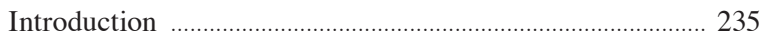

Material and methods ............................................................ 237

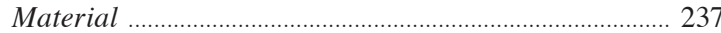

Anatomy and histology ..................................................... 237

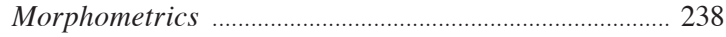

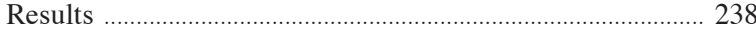

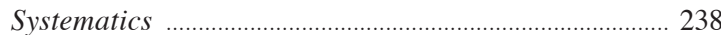

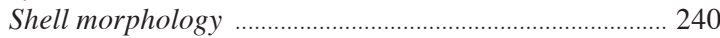

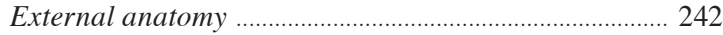

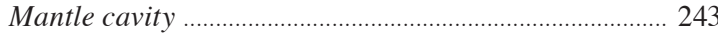

Alimentary system ................................................................. 244

Reno-pericardial system ................................................ 247

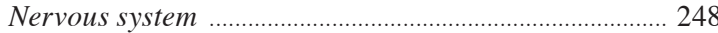

Reproductive system ……………………………................ 249

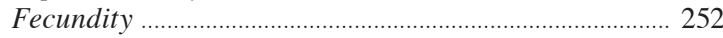

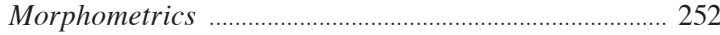

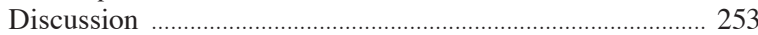

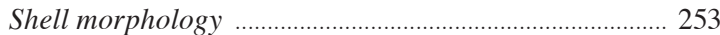

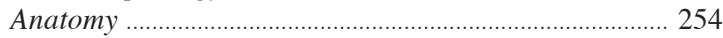

Functional morphology and evolutionary ecology ....... 259

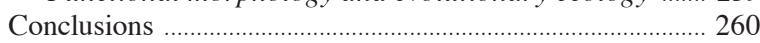

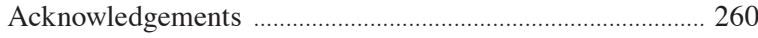

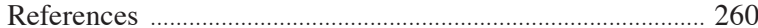

\section{Introduction}

The anatomy and functional morphology (i.e. how form is related to function in its broadest sense) of viviparid gastropods (Viviparidae) of the subfamily 
Bellamyinae are poorly documented, although substantial differences have been observed in comparison to other viviparid subfamilies, i.e. Viviparinae and Lioplacinae (Bouchet and Rocroi, 2005), particularly in reproductive anatomy (Rohrbach, 1937; Vail, 1977; Simone, 2004). For many of the approximately 125150 known viviparid species (Strong et al., 2008), limited anatomical and molecular data are available, leaving their position within the family and genus-level relationships uncertain (but see Sengupta et al., 2009; Du et al., 2013). Because of this lack of knowledge, no hypotheses exist as to how these differences in body plan among the subfamilies have arisen, how the subfamilies are phylogenetically related to one another, what the ancestral states were in the earliest viviparids (but see Starobogatov, 1992 for some suggestions), or what the functional advantages of one body plan over the others may be for each region of occurrence.

The family Viviparidae has a temperate to tropical global distribution (e.g. Prashad, 1928), but is not native to Antarctica or South America, although it has been introduced to the latter. The subfamilies had largely separate distributions until introductions brought them into contact, with conspicuous absences from large regions, e.g. the Middle East (Prashad, 1928), where the family was present during the PlioPleistocene (Sivan et al., 2006). The Bellamyinae is largely confined to the Old World tropics and subtropics, whereas the Lioplacinae has a Nearctic distribution, and the Viviparinae is Holarctic. As mentioned above, however, some opportunistic Asian species were introduced elsewhere: Cipangopaludina chinensis (Gray in Griffith and Pidgeon, 1833) and C.japonica (von Martens, 1861) were first brought to Northern America in $\sim 1892$ and $\sim 1911$, respectively, as a human food source (Prashad, 1928; Clench and Fuller, 1965), and very recently bellamyines have been discovered in South America (Sinotaia quadrata [Benson, 1842]) (Ovando and Cuezzo, 2012) and in Europe (C.chinensis) (Soes et al., 2011). Some bellamyines, such as the introduced species, appear to be relatively opportunistic and ecological generalists, but others, notably some African Bellamya, are more stenotopic, although they have radiated in some of the East African Rift lakes

Table 1. Specimens examined in anatomical and histological studies. Most organ systems were subjected to comparative studies in males and females. Dissected specimens received individual museum numbers (those collected from the Potomac River in Alexandria in 2012: USNM 1296930-1296947; from Lake Barcroft in 2013: USNM 1296948; and from Gunston Cove in 2014: USNM 1296844, 1296846, 1296850, and 1296952; see material and methods). On the first row (gross morphology) specimen numbers are followed by $\mathrm{M}$ or $\mathrm{F}$, indicating the sex of each specimen.

Organ system Specimens analyzed

Gross morphology

Pallial organs (general)

Respiratory system

Alimentary system

Reno-pericardial system

Nervous system

Male reproductive system

Female reproductive system all specimens (1296930M, 1296931F, 1296932F, 1296933F, 1296934M, 1296935M, 1296936M, 1296937M, 1296938M, 1296939F, 1296940F, 1296941F, 1296942M, 1296943M, 1296944M, $1296945 \mathrm{M}, 1296946 \mathrm{M}, 1296947 \mathrm{M}, 1296948 \mathrm{~F}, 1296844 \mathrm{~F}, 1296846 \mathrm{~F}, 1296850 \mathrm{~F}, 1296852 \mathrm{~F})$ $1296930 ; 1296931 ; 1296933 ; 1296934 ; 1296942 ; 1296947 ; 1296844$ 1296930 (gill); 1296931 (gill); 1296932 (gill + vascular system); 1296844 (gill + gill leaflet) 1296930 (gastric chamber, intestine, rectum); 1296931 (digestive gland); 1296932 (gastric chamber, intestine, rectum; histology of digestive gland); 1296933 (buccal apparatus and haemocoel, SEM of radula); 1296935 (buccal mass, haemocoel); 1296937 (gastric chamber); 1296940 (histology of digestive gland); 1296944 (gastric chamber, digestive gland including histology); 1296946 (gastric chamber, digestive gland); 1296947 (gastric chamber); 1296948 (gastric chamber, digestive gland); 1296844 (buccal mass, gastric chamber, digestive gland); 1296846 (gastric chamber)

1296930 (pericardium); 1296931 (kidney); 1296932 (ureter, kidney); 1296933 (pericardium, vascular system); 1296934 (kidney, pericardium); 1296937 (pericardium, pallial vascular system); 1296941 (pericardium); 1296850 (pericardium)

1296933 (nerve ring, nerves in haemocoel); 1296935 (nerve ring); 1296844 (nerve ring) 1296930 (right tentacle, prostate, testis); 1296934 (testis); 1296935 (right tentacle, prostate); 1296942 (testis, including histology); 1296947 (testis)

1296932 (seminal receptacle, copulatory bursa, albumen gland, brood pouch); 1296933 (seminal receptacle, renal oviduct, copulatory bursa, albumen gland, brood pouch, SEM of juveniles); 1296939 (brood pouch); 1296941 (brood pouch); 1296948 (seminal receptacle including histology, copulatory bursa incl. histology, albumen gland incl. histology, brood pouch), 1296844 (ovary, visceral oviduct, seminal receptacle, copulatory bursa, albumen gland, brood pouch), 1296850 (ovary), 1296852 (anatomy and histology of the seminal receptacle, copulatory bursa and albumen gland) 
and paleolakes (Brown, 1994; Van Bocxlaer and Hunt, 2013; Salzburger et al., 2014; Schultheiß et al., 2014).

Despite general uncertainty of genus-level affiliations and the limited availability of comparative data for several viviparid genera, the genera Bellamya Jousseaume, 1886, Idiopoma Pilsbry, 1901, Cipangopaludina Hannibal, 1912 and presumably Neothauma Smith, 1880 show similar anatomical features that allow classification in the Bellamyinae (e.g. Rohrbach, 1937). Anatomical characters of the Australian viviparids Notopala Cotton, 1935 and Larina Adams, 1854 also warrant classification as bellamyines (Simone, 2004), like the Asian genera Filopaludina Habe, 1964 (with its subgenenera Filopaludina s.s. and Siamopaludina Brandt, 1968), Trochotaia Brandt, 1974, Eyriesia Fischer, 1885, Mekongia Crosse and Fischer, 1876, Sinotaia Haas, 1939, Anulotaia Brandt, 1968 (Brandt, 1974), Angulyagra Rao, 1931 (Du et al., 2013), and also Margarya Nevill, 1877 and Taia Annandale, 1918 (Vail, 1977). Hence, Bellamyinae is the most diverse viviparid subfamily as Lioplacinae and Viviparinae each contain two confirmed genera (Campeloma Rafinesque, 1819 and Lioplax Troschel, 1856, Viviparus de Montfort, 1810 and Tulotoma Haldeman, 1840, respectively) (Vail, 1977). Great diversity but limited systematic control and coverage in anatomical studies in comparison to Viviparinae and Lioplacinae (e.g. Leydig, 1850; Baudelot, 1863; Auerbach, 1896; Crabb, 1929; Mattox, 1938; Vail, 1977) make the subfamily Bellamyinae an appropriate target for additional comparative anatomical work. Moreover, an improved understanding of the intrinsic biological properties of the group is a key requirement to comprehend the evolutionary history, the ecology and the invasion biology of the Bellamyinae, notably those properties that may have played a key role in their diversification and evolutionary success.

Here we study the anatomy and life history of $C$. japonica, a relatively familiar bellamyine with important implications for biological conservation of benthic ecosystems due to its introductions in the Neotropics. The species remains poorly studied, and as a result many misconceptions exist in the literature on the systematics, anatomy and functional morphology of $C$. japonica (e.g. Smith, 2000). We perform morphological, anatomical and histological investigations of $C$. japonica to understand how form and function relate to one another, and how they have affected the evolutionary ecology of the species. Subsequently we combine our findings with literature data to build a comparative framework for life history studies of viviparids in general.

\section{Material and methods}

\section{Material}

Living specimens and empty shells of $C$. japonica were collected in September 2012 from the Potomac River in Alexandria, VA (living specimens at $38.8103^{\circ}$ $\mathrm{N}, 77.0393^{\circ} \mathrm{W}$ and $38.8137^{\circ} \mathrm{N}, 77.0380^{\circ} \mathrm{W}$; empty shells between $38.8154^{\circ} \mathrm{N}, 77.0381^{\circ} \mathrm{W}$ and $38.8101^{\circ}$ $\left.\mathrm{N}, 77.0393^{\circ} \mathrm{W}\right)$. Other living specimens were collected in October 2013 from Lake Barcroft, VA (38.8529 $\left.\mathrm{N}, 77.1552^{\circ} \mathrm{W}\right)$, and in June 2014 from Gunston Cove, VA $\left(38.6817^{\circ} \mathrm{N}, 77.1533^{\circ} \mathrm{W}\right)$. Living specimens were heat-shocked (Fukuda et al., 2008), then preserved in $80 \%$ ethanol for use in studies of the external gross morphology and detailed functional anatomy. 23 specimens were used in anatomical studies; a total of 53 shells were used for the study of shell morphology and allometry. This material is deposited at the Smithsonian Institution, National Museum of Natural History (Potomac River: USNM 1296930-1296947; Lake Barcroft: USNM 1296948; Gunston Cove: USNM 1296844, 1296846, 1296850, 1296952 and 1296902).

\section{Anatomy and histology}

Even after heat shocking the specimens, it was not possible to remove bodies from the shells without damaging the tissues, especially the more voluminous females. Hence, voucher images were made after which the shells were broken with a vice, soft tissues were removed, and individuals sexed. Anatomical dissections were made using a Wild M5 and Leica MZ16 microscope with camera lucida. Staining with toluidine blue was used to enhance contrast when necessary. Most organ systems were studied in multiple specimens to allow differentiation between individual variation and characteristics that define the population, and by extension the species (Table 1). Anatomical renderings consist of a baseline drawing for a representative specimen, which was subsequently modified into a more generalized representation.

Histological sections were prepared from the testis of males (not shown), and the albumen and capsule glands of females. Target organs were dissected, dehydrated through a graded ethanol series, cleared in xylene, embedded in paraplast, and serially sectioned at 7-8 $\mu \mathrm{m}$. Sections were stained with haematoxylin and eosin-phloxine following standard protocols (Humason, 1967); cover slips were mounted with a solution of permount and $5 \%$ terpenol, dissolved in toluene. 
Histological sections were viewed and photographed with a Leica DMLS2 compound microscope and a Leica DFC320 digital camera.

Radulae were isolated, cleaned in diluted bleach, sonicated, mounted on SEM stubs with adhesive tabs, sputter coated with 25-30 nm gold/palladium (60/40) and studied with a Hitachi TM3000 tabletop scanning electron microscope (SEM).

Embryos and developing juveniles from the brood pouch of seven anatomically-studied females that were collected in September 2012 were removed and quantified to provide an insight into fecundity.

\section{Morphometrics}

To explore sexual dimorphism and allometric variation in shell morphology, we applied semi-landmark morphometrics with 10 landmarks and 4 open semilandmark curves (Fig. 1) to 53 shells of $C$. japonica that represent a growth series, including 20 sexed adult specimens. For the allometric studies, five juvenile specimens obtained from the anteriormost part of the

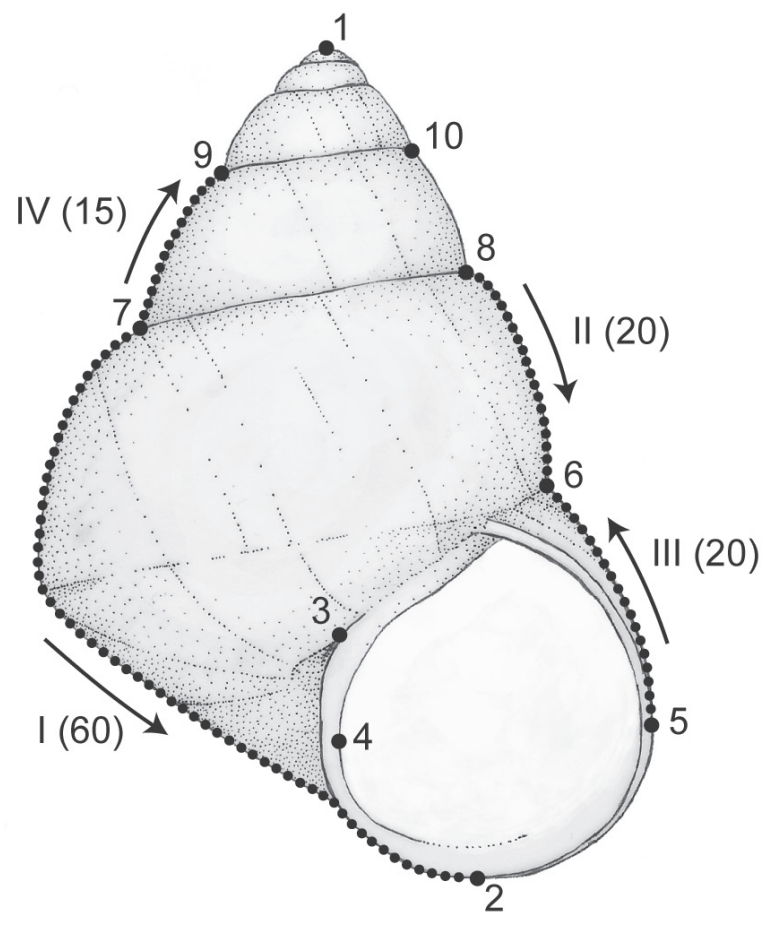

Fig. 1. Generalized viviparid shell in apertural view with landmarks (Arabic numerals), semi-landmark curves (Roman numerals with the number of points per curve indicated in parentheses) and the direction of digitization (arrows) as used in this study. brood pouch were used as a baseline. These specimens reflect juvenile shell morphology at birth. Juveniles were cleaned following the protocol used for radula cleaning (see methods for anatomy and histology), mounted on SEM stubs with carbon adhesive tabs, sputter coated and photographed in apertural view with the abovementioned SEM. Larger, more mature specimens were photographed in the same view with a Canon EOS 350D SLR camera equipped with an EFS $60 \mathrm{~mm} \mathrm{f} / 2.8$ Macro USM lens.

For morphometric analyses, we used semi-landmark morphometrics following the recommendations of Van Bocxlaer and Schultheiß (2010), using the modified protocol of Van Bocxlaer and Hunt (2013). Digital images were compiled in .tps format using TpsUtil 1.50 (Rohlf, 2012). Landmarks and semi-landmark curves were digitized in TpsDig 2.16 (Rohlf, 2010). These curves were anchored between landmarks (LM7 \& 2, LM8 \& 6, LM5 \& 6 and LM 7 \& 9, respectively; Fig. 1) and each consists of a fixed number of equidistant points that were sampled via the resample-curveby-length option in TpsDig 2. Specimens were aligned using Procrustes superimpositioning in CoordGen6h (Sheets, 2008), after which the semi-landmarks were slid along their respective curve using the minimum Procrustes distance criterion in SemiLand6 (Sheets, 2008). The resulting Procrustes superimposition coordinates document shell shape, and shell height was measured in Klonk Image Measurement Light version 14.1.1.7 and logarithmically transformed in base $e$. Morphometric shape data and size measurements were imported in R 3.0.1 (R Development Core Team, 2013) for further analysis using Vegan 2.0-8 (Oksanen et al., 2013) and Boot 1.3-9 (Ripley, 2013). The Procrustes superimposition coordinates were subjected to Principal Component Analysis (PCA). Relevant principal components were plotted against shell height to assess allometric changes. For PC1 a linear relationship was obtained which was investigated with linear least squares regression.

\section{Results}

\section{Systematics}

Family Viviparidae Gray, 1847

Subfamily Bellamyinae Rohrbach, 1937

Genus Cipangopaludina Hannibal, 1912

Type species: Paludina malleata Reeve, 1863, by original designation. 
Remarks. Adult shells of Cipangopaludina species are usually very similar to those of Idiopoma, but are larger and have a more inflated body whorl; unlike in many Idiopoma species, brownish zones above and below the periphery of the whorls are lacking; embryonic and juvenile whorls of Cipangopaludina are adpressed, with a peripheral, basal angulation and often two spiral ridges, whereas the embryonic shells of Idiopoma are less adpressed, more globose and never keeled; embryonic shells have numerous spiral lines, the three most prominent bear long, curved periostracal hairs, whereas embryonic shells of Idiopoma lack periostracal hairs entirely; mantle edge is thickened in Cipangopaludina compared to Idiopoma; other anatomical differences are largely unknown.

The relationships of Asian viviparids are poorly understood and, hence, the literature contains much discussion and speculation on the genus-group classification within the Bellamyinae, including the circumscription and affinities of Cipangopaludina Hannibal, 1912. Material classified here as Cipangopaludina was earlier grouped in Viviparus (e.g. Pilsbry, 1902; Kuroda, 1929; Thiele, 1929; Clench and Fuller, 1965), and has also been referred to Vivipara Sowerby, 1813 (e.g. Hannibal, 1911), an incorrect subsequent spelling, and to Paludina Férussac, 1812 (e.g. von Martens, 1861; Kobelt, 1879; Fischer, 1887), an invalid name placed on the Official Index of Rejected and Invalid Generic Names in Zoology in 1959 by ICZN Opinion 573. Hannibal (1912) described Cipangopaludina, with the Japanese species Paludina malleata Reeve, 1863 as type species, as a subgenus of Idiopoma. The latter was proposed with Vivipara henzadensis Pilsbry, 1901 as type species, which is considered to be a form of the Indian species Nerita dissimilis Müller, 1774 (Brandt, 1974). However, ambiguity remained concerning the status of Idiopoma and other viviparid genera. Some authors raised Cipangopaludina to genus level (e.g. Yen, 1943), whereas others (e.g. Prashad, 1928; Thiele, 1929) lumped it and many other genera that currently belong to the three subfamilies into a single genus, Viviparus, with several subgenera. Annandale (1920) proposed the genus Lecythoconcha with Paludina lecythis Benson, 1836 as type species, to which the species Paludina japonica von Martens, 1861 would belong based on the generic description and geographic coverage. This classification was maintained by some (Rao, 1925), but others (Prashad, 1928; Kuroda, 1929; Brandt, 1974) synonymized Lecythoconcha with Cipangopaludina. Rohrbach (1937) listed only a single large genus in his subfamily Bellamyinae for Afri- can and Asian viviparids, namely Bellamya Jousseaume, 1886. Other authors (e.g. Yen, 1943; Brandt, 1974) assigned several genera to the Bellamyinae, and Bellamya and Cipangopaludina were hypothesized to be closely related but separate genera. Recently, Smith (2000) proposed to accommodate Cipangopaludina as a subgenus of Bellamya based on anatomical data, which was followed by others (Solomon et al., 2010). However, the type species of Bellamya is Bellamya bellamya Jousseaume, 1886, by original designation, which is considered a synonym of Vivipara duponti De Rochebrune, 1881 (Germain, 1920), and represents a West African form of Bellamya unicolor (Olivier, 1804) (Brown, 1994). Bellamya unicolor is nested in a clade of African viviparids and a deep phylogenetic split exists between African and Asian viviparids (Sengupta et al., 2009; Du et al., 2013; Schultheiß et al., 2014). Based on fossil calibration, the base of the African clade would date to $\sim 15$ Ma or possibly older (Schultheiß et al., 2014), and a clade consisting of species of Angulyagra (= a replacement name for Dactylochlamys Rao, 1925), Filopaludina, Larina and Taia is more closely related to the African viviparids than the clade containing species of Cipangopaludina, Margarya, Mekongia, and Sinotaia (Sengupta et al., 2009; Du et al., 2013). Consequently, synonymizing Cipangopaludina with Bellamya does not accurately reflect evolutionary relationships. Other Asian species like Idiopoma dissimilis also appear deeply divergent from African Bellamya species, and we consider it likewise ill-founded to consider Idiopoma a junior synonym or subgenus of Bellamya. Further work is required to assess the relationship of Asian viviparids and their genus-level classification.

Cipangopaludina japonica (von Martens, 1861)

Paludina japonica von Martens, 1861: 44. Type locality: Japan.

Viviparus japonicus var. iwakawa Pilsbry, 1902, p. 117, pl. 9, fig. 3. Type locality: Furukawa, Rikuzen, Japan.

Other references:

Paludina japonica - Reeve 1863, pl. 3, figs 13a,b. Kobelt 1879: 120, pl. 11, fig. 1.

Paludina oxytropis - Kobelt, 1879: 123, pl. 11, fig. 6. - Iwakawa 1897: 88, figs 8-17.

Viviparus japonicus - Pilsbry 1902: 117, pl 9, fig. 1.

Remarks. Hannibal proposed Cipangopaludina as a subgenus of Idiopoma for Paludina malleata from Japan, but considered japonica to belong to Idiopoma 
s.s. Paludina malleata is regularly considered a synonym of P. chinensis (see e.g. Jokinen, 1982), a species illustrated by Gray without description. However, Reeve (1863) noted the native range of chinensis to be Chusan (Eastern China), whereas the type locality of malleata is Japan. Both taxa may hence belong to deeply divergent clades, and molecular analysis of topotypic specimens of chinensis and malleata are required before synonymizing these species. Cipangopaludina japonica also has been synonymized with $C$. chinensis (e.g. Dundee, 1974; Clarke, 1978), however others have considered the morphological differences to be sufficiently large to retain them as separate species (Clench and Fuller, 1965; Stańczykowska et al., 1971; Jokinen, 1982; Smith, 2000; Solomon et al., 2010), which has been confirmed by molecular analyses (Hirano et al., 2015). Rigorous molecular studies are also required to elucidate the relationships of $C$. malleata and C. japonica. Ideally, these would also include specimens of $C$. stelmaphora (Kobelt, 1879) described from Japan, which may be a synonym of $C$. japonica.

\section{Shell morphology}

Juvenile specimens from the anteriormost brood pouch of four whorls (Fig. 2A, B); embryonic shell elevated above the teleoconch and comprising $~ 1.2$ whorls, but variable and in some populations comprising up to 2 whorls (Fig. 2C); apical cap of the embryonic shell bears an outer furrow or crease (Fig. 2D); transition between the embryonic shell and the teleoconch inconspicuous, marked by a sudden but slight increase in diameter of the whorl; ornament of fine spiral threads are present, but the apical part of the embryonic shell has no hairs on these threads; spiral rows of axial striae may be present (Fig. 2D, E) between the spiral threads.

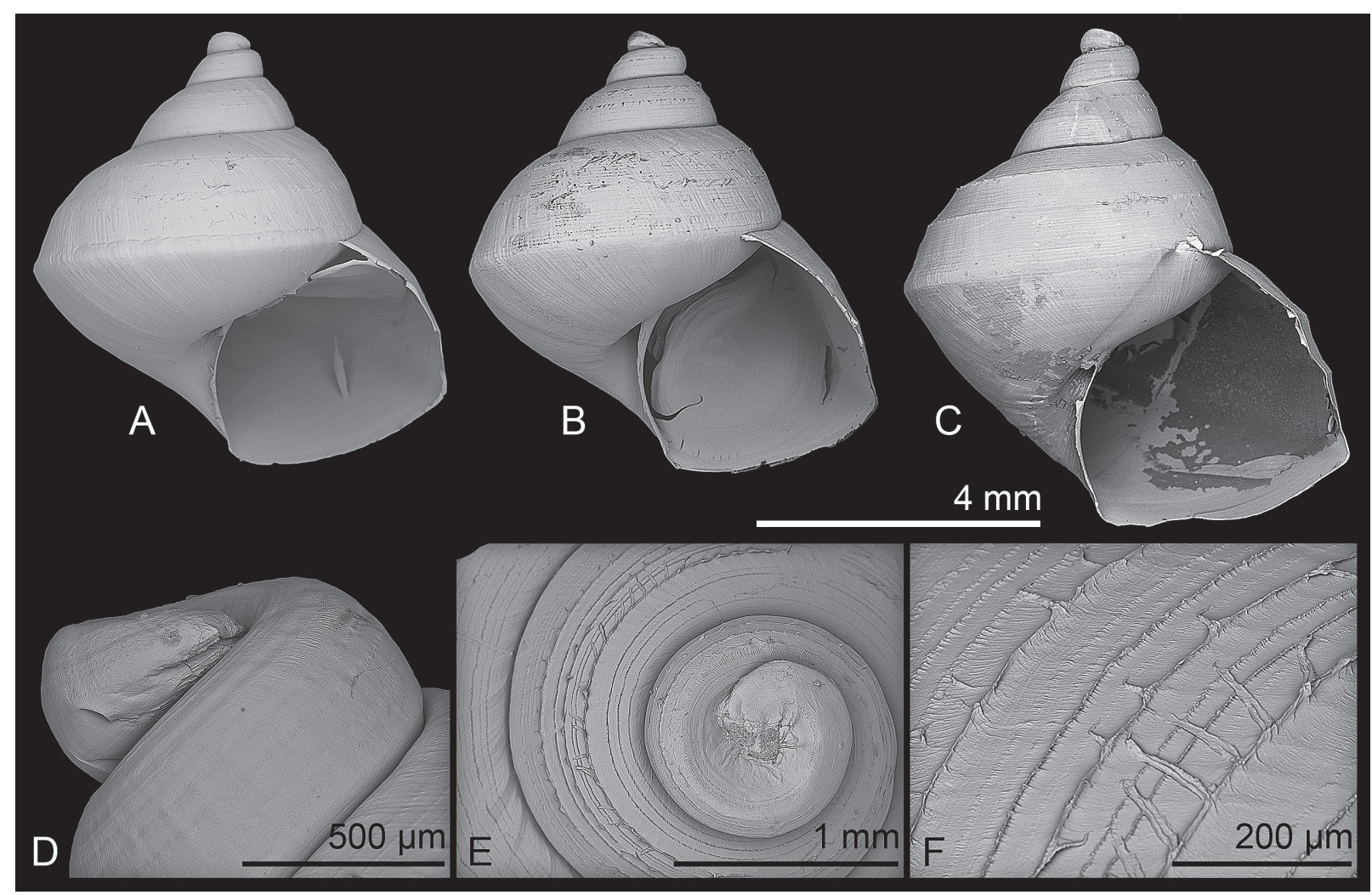

Fig. 2. Juvenile shell morphology of Cipangopaludina japonica. A, B) Juveniles extracted from the anteriormost pallial oviduct of specimen USNM 1296933 (population from the Potomac River in Alexandria, USA), and C) of a female from a Japanese population (USNM 424320) for comparison. Note the higher, more acute spire and the slightly more angular body whorl of the Japanese specimen compared to those from the USA. D) Apical cap of the embryonic shell, showing the apical outer furrow or crease. E, F) Apical view showing periostracal hairs and spiral threads. 
Early teleoconch with a bluntly-angular basal carina and two prominent spiral cords (Fig. 2E) corresponding to periostracal ridges with long hairs; some variation exists in the translation of the first teleoconch whorls (hence, the apical angle), and in the angularity of the cords and the basal carina (compare Fig. 2A-C); midway between the two cords is a third spiral thread with shorter hairs; shell does not have pits at the insertion of hairs; many other, finer spiral threads without hairs are present (Fig. 2E, F); axial sculpture consisting of abundant fine, prosocline growth lines that become more prominent with age; on the juvenile shell they intersect with the spiral elements to give the shell a finely reticulate texture.
Subadult shells (Fig. 3A-E) have a pronounced basal angulation that becomes less conspicuous with age; early whorls usually display two conspicuous cords, and are adpressed, whereas later whorls are not; aperture of subadults somewhat angulate below; adult shells have a more smoothly rounded, inflated penultimate and body whorl than those of juveniles and subadults (compare Fig. 3A-E with 3F-H); adult shells typically lack the basal angulation and cords of juveniles and subadults but may display more or less conspicuous spiral lines in corresponding positions (Fig. 3F); sutures become more deeply impressed, the shoulder more rounded, and the whorls more inflated as the shell grows; spire high, spiral angle $\sim 84^{\circ}$ in juveniles and

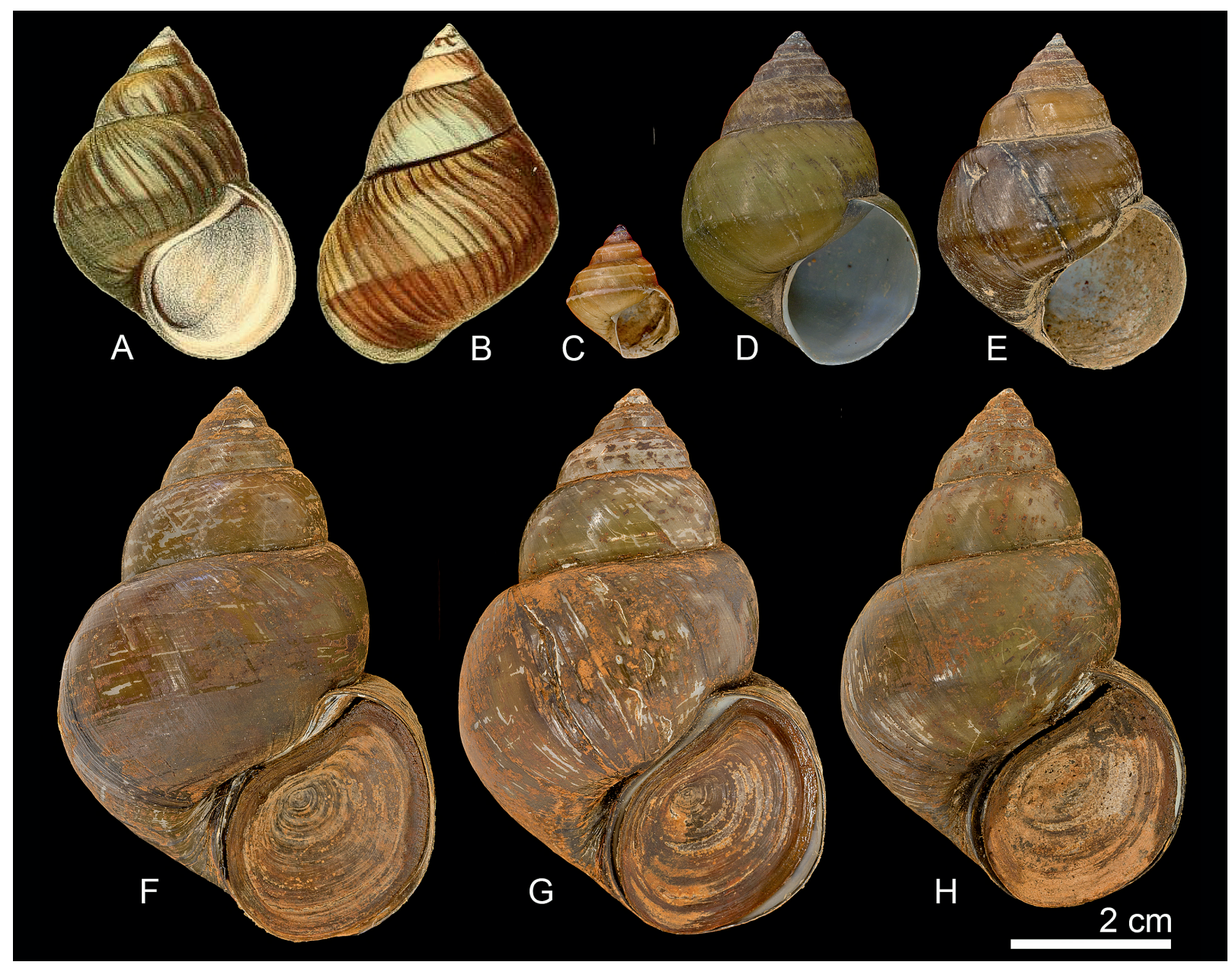

Fig. 3. Subadult and adult shell morphology of Cipangopaludina japonica. A, B) Apertural and adapertural views as illustrated by Reeve (1863). C) Post-birth juvenile showing strongly angulated early whorls. D, E) Subadults showing the characteristically angulated base of the body whorl. F-H) Large adults. F and G are females, with slightly more inflated body whorls than males (H). Scale bar for $\mathrm{C}-\mathrm{H}$; the size of Reeve's specimen was unspecified. 
$\sim 74^{\circ}$ and $\sim 68^{\circ}$ in adult females and males, respectively (compare Fig. 3H with 3F, G); shape of the adult aperture large and ovate, narrower adapically, with a wellrounded base; parietal callus present, but not very pronounced; umbilicus open.

\section{External anatomy}

Operculum (Fig. 4C) corneous, sub-pyriform, thick, slightly translucent, brown in color, thicker and darker at the parietal and columellar margins than at the palatal one; growth concentric, but faster at the palatal margin, resulting in a subcentral nucleus (i.e. 1/4-1/3 of the total width from the columellar margin).

Soft tissues of adult specimens comprising $~ 3.5$ whorls (Fig. 4); foot broad, muscular with a long, shallow pedal gland along the anterior margin of the propodium. Columellar muscle moderately long, extending 0.5-1.0 whorl posteriorly. Cephalic tentacles short and thick in preserved specimens, up to roughly twice the length of the snout; right cephalic tentacle modified in males to a penis with a terminal gonopore (Fig. 5). Eyes terminal on short ocular peduncles at outer bases of cephalic tentacles. Neck modified on the right into a tall, broad nuchal lobe at the level of the urinary pore, the anus and (in females) the female gonopore at the right side of the mantle cavity, just behind the thick, muscular mantle edge (Fig. 5). It can be extended somewhat beyond the shell, whereas the smaller, shorter left nuchal lobe cannot.
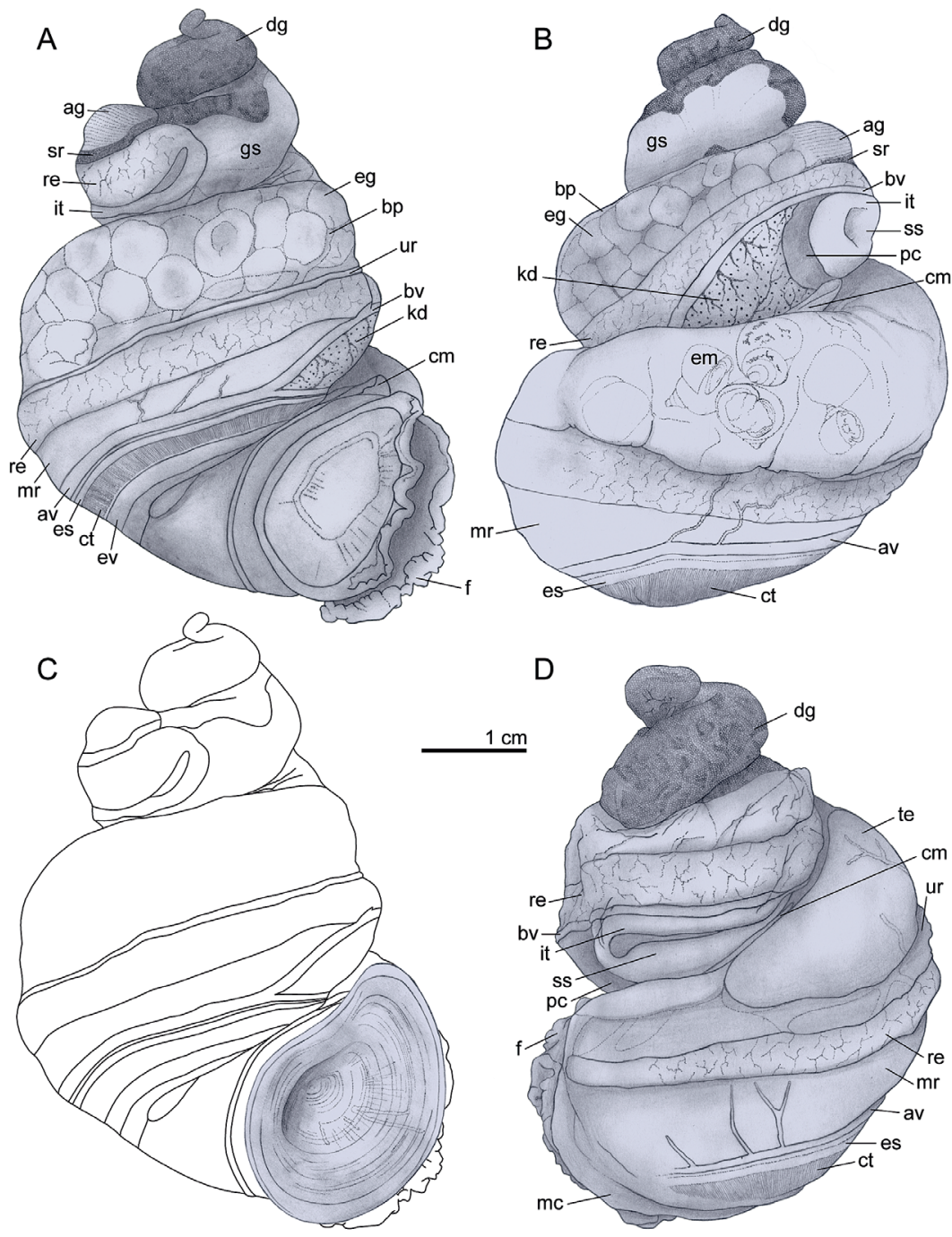

B

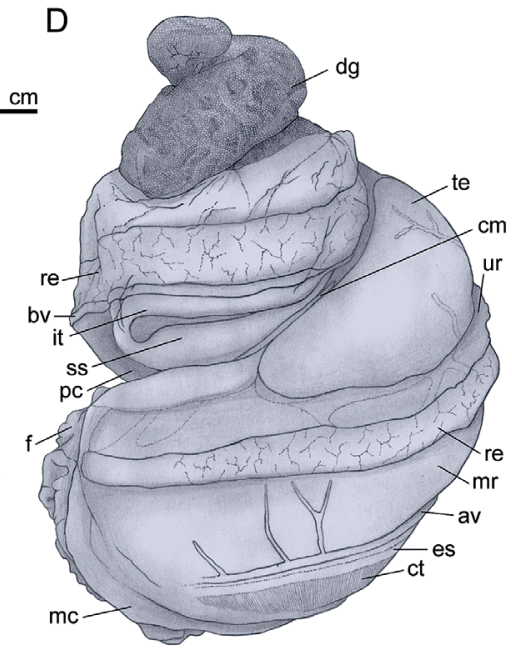

Fig. 4. Body morphology and anatomy. A) Female in apertural view; B) Female in adapertural view; C) operculum morphology; D) Male in abapertural view. Abbreviations: ag = albumen gland; av = afferent branchial vessel; bp = brood pouch; bv = blood vessel; $\mathrm{cm}=$ columellar muscle; $c t=$ ctenidium; $\mathrm{dg}=$ digestive gland; eg = egg; em = embryo; es = endostyle; ev = efferent branchial vessel; $\mathrm{f}=$ foot; gs = gastric chamber; it = intestine; $\mathrm{kd}=$ kidney; $\mathrm{mc}=$ mantle collar; $\mathrm{mr}$ $=$ mantle roof; $\mathrm{pc}=$ pericardium; $\mathrm{re}=$ rectum; sr = seminal receptacle; ss = style sac; te $=$ testis; ur $=$ ureter. 


\section{Mantle cavity}

Mantle cavity (Fig. 5) long, usually somewhat shorter in males ( $\sim 1.0$ whorls) than in females ( 1.5 whorls) and bounded posteriorly by the reno-pericardial system. On the mantle floor, slightly to the left of the midline, a conspicuous food groove extends from the posterior ctenidium to the head; a prominent ridge marks the base of the food groove and anteriorly fuses with the right nuchal lobe, forming a trough that is deflected around the cephalic tentacle and continues anteriorly towards the mouth. The monopectinate ctenidium is composed of elongate triangular leaflets (Fig. 5, inset) and extends along the left mantle roof from near the mantle collar to the posterior end of the cavity. At the

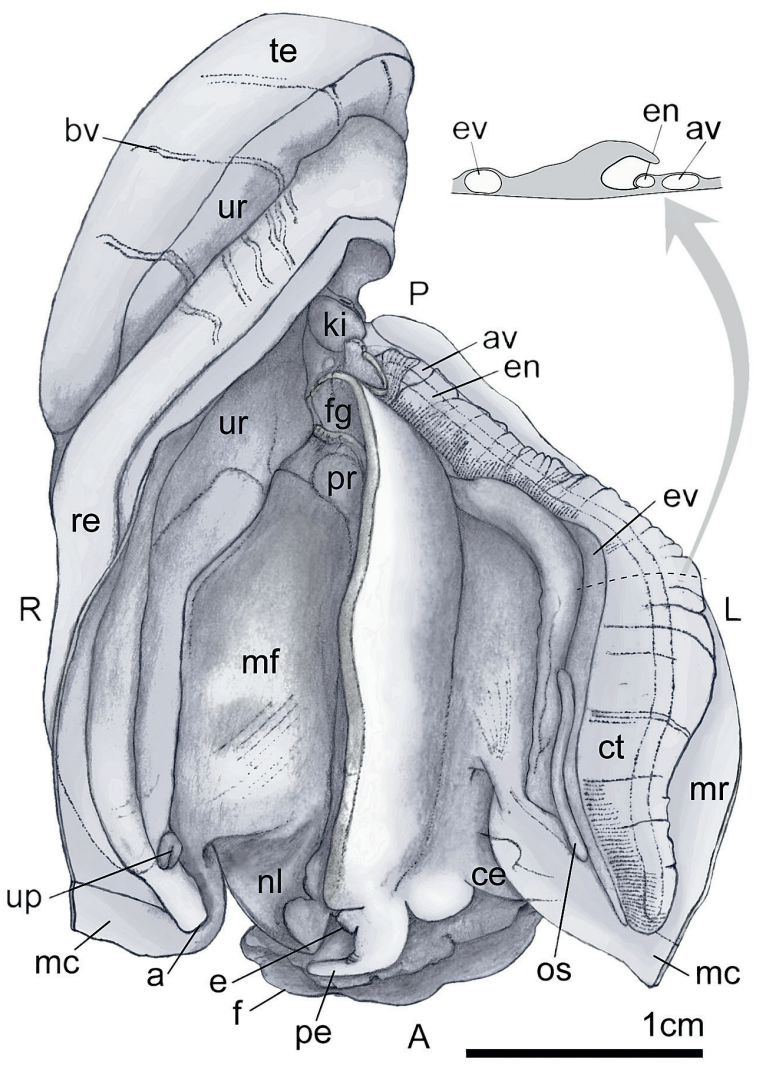

Fig. 5. Mantle cavity morphology of a male, with inset of a single gill filament. Orientation: $\mathrm{A}=$ anterior; $\mathrm{L}=$ left; $\mathrm{P}=$ posterior; $\mathrm{R}=$ right . Abbreviations: $\mathrm{a}=$ anus; $\mathrm{av}=$ afferent branchial vessel; bv = blood vessel; ce = cephalic tentacle; $c$ ct = ctenidium; $\mathrm{e}=$ eye en = endostyle; $\mathrm{ev}=$ efferent branchial vessel; $\mathrm{f}=$ foot; $\mathrm{fg}=$ food groove $; \mathrm{ki}=$ kidney; $\mathrm{mc}=$ mantle collar; $\mathrm{mf}=$ mantle floor; $\mathrm{mr}=$ mantle roof; $\mathrm{nl}=$ nuchal lobe; os = osphradium; pe $=$ penis $; \mathrm{pr}=$ prostate re = rectum; te = testis; $\mathrm{up}=$ urinary pore; ur $=$ ureter. anteriormost third of the gill, overlying the large efferent branchial vein, lies the slender osphradium, which forms a ridge with distinct papillae along the side facing the ctenidial axis, likely representing vestigial leaflets. The endostyle runs along the length of the afferent axis of the ctenidium (Fig. 4A, B, D, 5); posteriorly the endostyle wraps around the base of the ctenidium and is continuous with the posterior end of the food groove. The hypobranchial gland is weakly developed. At or near the dorsal midline lies the rectum, and further to the right the ureter and pallial gonoduct (testis or

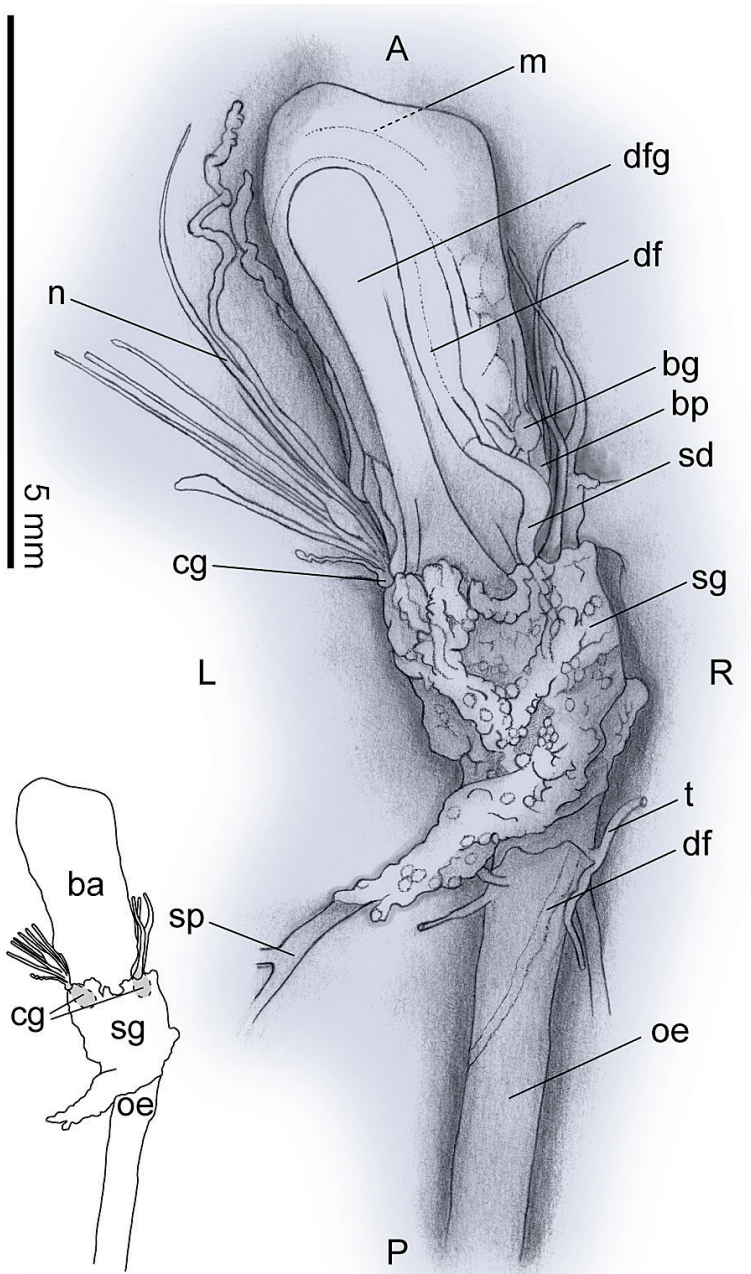

Fig. 6. Dorsal view of buccal apparatus and mid-oesophagus, inset with a schematic representation. Orientation: $\mathrm{A}=$ anterior; $\mathrm{L}=$ left; $\mathrm{P}=$ posterior; $\mathrm{R}=$ right. Abbreviations: $\mathrm{ba}=$ buccal apparatus; $\mathrm{bg}=$ buccal ganglion; $\mathrm{bp}=$ buccal pouch; $\mathrm{cg}=$ cerebral ganglion (largely concealed by salivary gland); $\mathrm{df}=$ dorsal fold; $\mathrm{dfg}=$ dorsal food groove; $\mathrm{m}=$ mouth; $\mathrm{n}=$ nerve; oe $=$ oesophagus; $\mathrm{sd}=$ salivary gland duct; $\mathrm{sg}=$ salivary gland; $\mathrm{sp}=$ supra-oesophageal ganglion; $\mathrm{t}=$ tensor. 

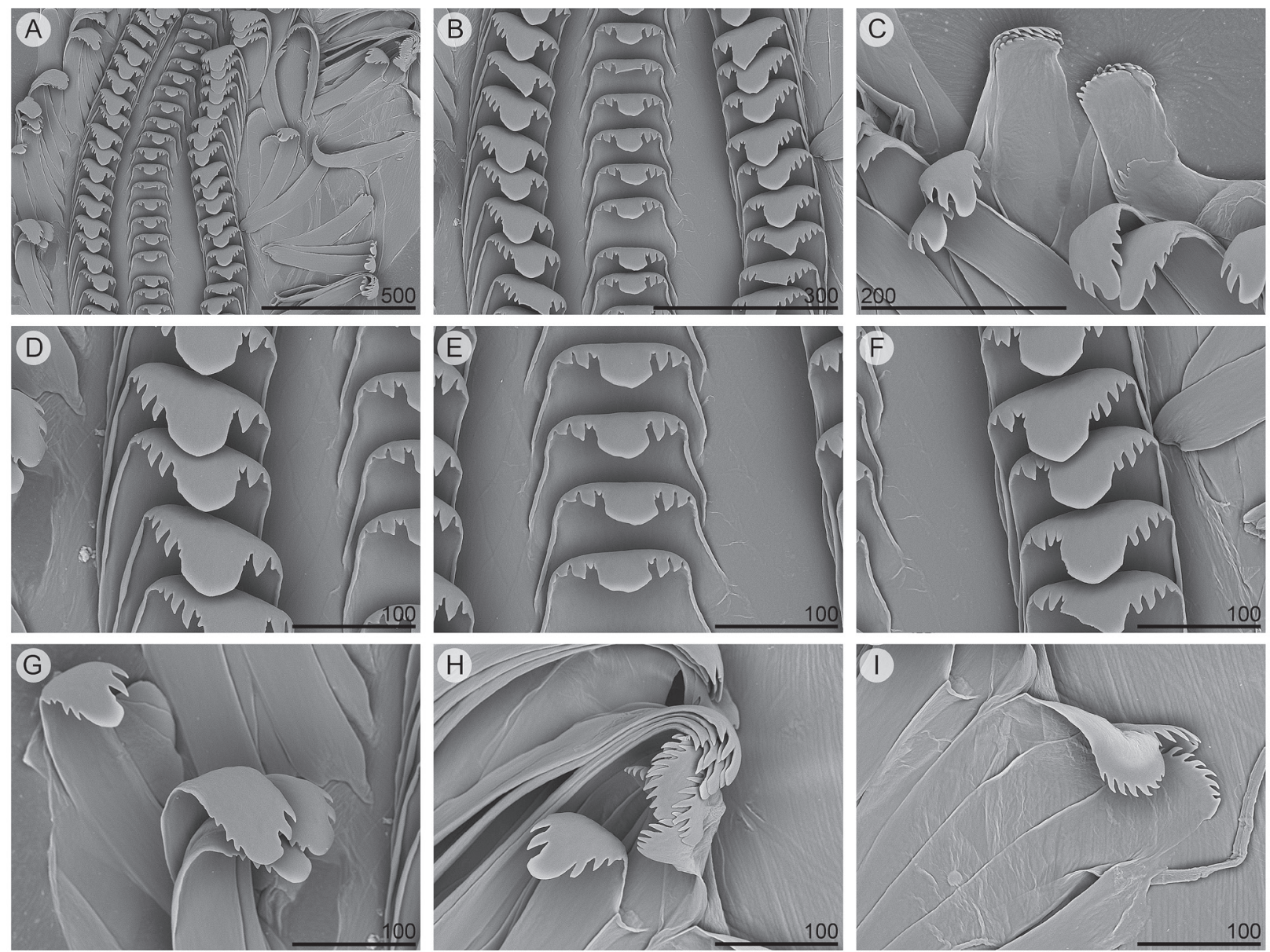

Fig. 7. Radular morphology. A) Section of anterior radular ribbon; B) Detail of rachidian and lateral teeth; C) Detail of inner and outer marginal teeth; D, F) Lateral teeth; E) Rachidian; G-H) Inner marginal teeth; H-I) Outer marginal teeth. Scale bars in $\mu \mathrm{m}$.

brood pouch) are present. The slit-like urinary pore opens slightly behind the papillate anus, which opens near the mantle edge.

\section{Alimentary system}

Buccal apparatus. Mouth forming transverse slit, opening ventrally at anterior end of the smooth oval snout; buccal mass long and slender (Fig. 6). Odontophore occupying $4 / 5$ of the length of the buccal mass, with narrowly triangular subradular organ projecting below the radula near the mouth. A small, thin paired jaw at the anterior end of the dorsal folds flanks the mouth dorsolaterally. Shallow, non-glandular buccal pouches are elaborated below the dorsal folds in the anteriormost oesophagus, just behind the buccal ganglia. Two salivary gland ducts open dorsolaterally alongside the dorsal food groove in the dorsal folds, shortly behind the middle of the buccal apparatus; the ducts pass posteriorly through the circumoesophageal nerve ring, to the large, massive salivary glands, which cover the nerve-ring dorsally and laterally, and parts of the foregut and the supra-oesophageal connective. Thick buccal retractors extend laterally from the rear of the buccal mass and insert on the walls of the cephalic hemocoel just anterior to the nerve ring. The radular sac is short, projecting ventrally slightly past the end of the buccal mass and through the nerve ring.

Radula. The radula is small $(\sim 6 \mathrm{~mm}$ in length in adults), slender and delicate, taenioglossate with $\sim 80$ rows of developed radular teeth, and several more rows of developing teeth (Fig. 7). The rachidian (Fig. 7A, B, E) possesses a broad, angular central cusp flanked by 
one very small cusp and two larger ones that decrease outwardly in size, giving the functional surface of the rachidian an obtuse, isosceles triangular appearance, but with marked gaps adjacent to the central cusp. The lateral teeth (Fig. 7A, B, D, F) are similar in width but longer than the rachidian, and somewhat asymmetrical. They have a larger central cusp than the rachidian, which is flanked by one small and two larger inner cusps, and by one or two small and four larger outer cusps. The inner marginal teeth (Fig. $7 \mathrm{C}, \mathrm{G}, \mathrm{H}$ ) are more asymmetrical than the lateral teeth, with long slender shafts and a cutting edge with one large, rounded median cusp flanked by two inner and three outer smaller cusps. The outer marginal teeth (Fig. 7C, $\mathrm{H}, \mathrm{I}$ ) have slightly broader shafts than the inner marginals, and are slightly bowed outwardly toward the base, with a broadly rounded cutting edge bearing eight cusps of more or less similar size and shape, but decreasing somewhat in size toward the outer edges.

Oesophagus. The anterior oesophagus emerges from the dorso-posterior side of the buccal apparatus and forms a simple tube bearing continuations of the dorsal folds and dorsal food groove (Fig. 6). In the mid-oesophagus, which starts just behind the nerve ring, the continuation of the dorsal folds and the dorsal food groove displays the effects of torsion. The walls of the oesophagus between the dorsal folds bear fine, irregular longitudinal ridges. The mid-oesophagus continues posteriorly as a simple tube in a central position, slightly to the right of the food groove, with no outpocketings or glandular elaborations, and deflects slightly towards the right at the posterior part of the mantle cavity to continue posteriorly along the columellar aspect, passing below the reno-pericardial complex. The posterior oesophagus is finely longitudinally ridged and widens substantially just before opening ventrally to the posterior gastric chamber.

Gastric chamber. The gastric chamber (Fig. 8) occupies most of the body just behind the elongate pericardium. It lies embedded in the lobes of the digestive gland and has non-muscular, thin walls. A prominent T-shaped ridge partially compartmentalizes the gas-

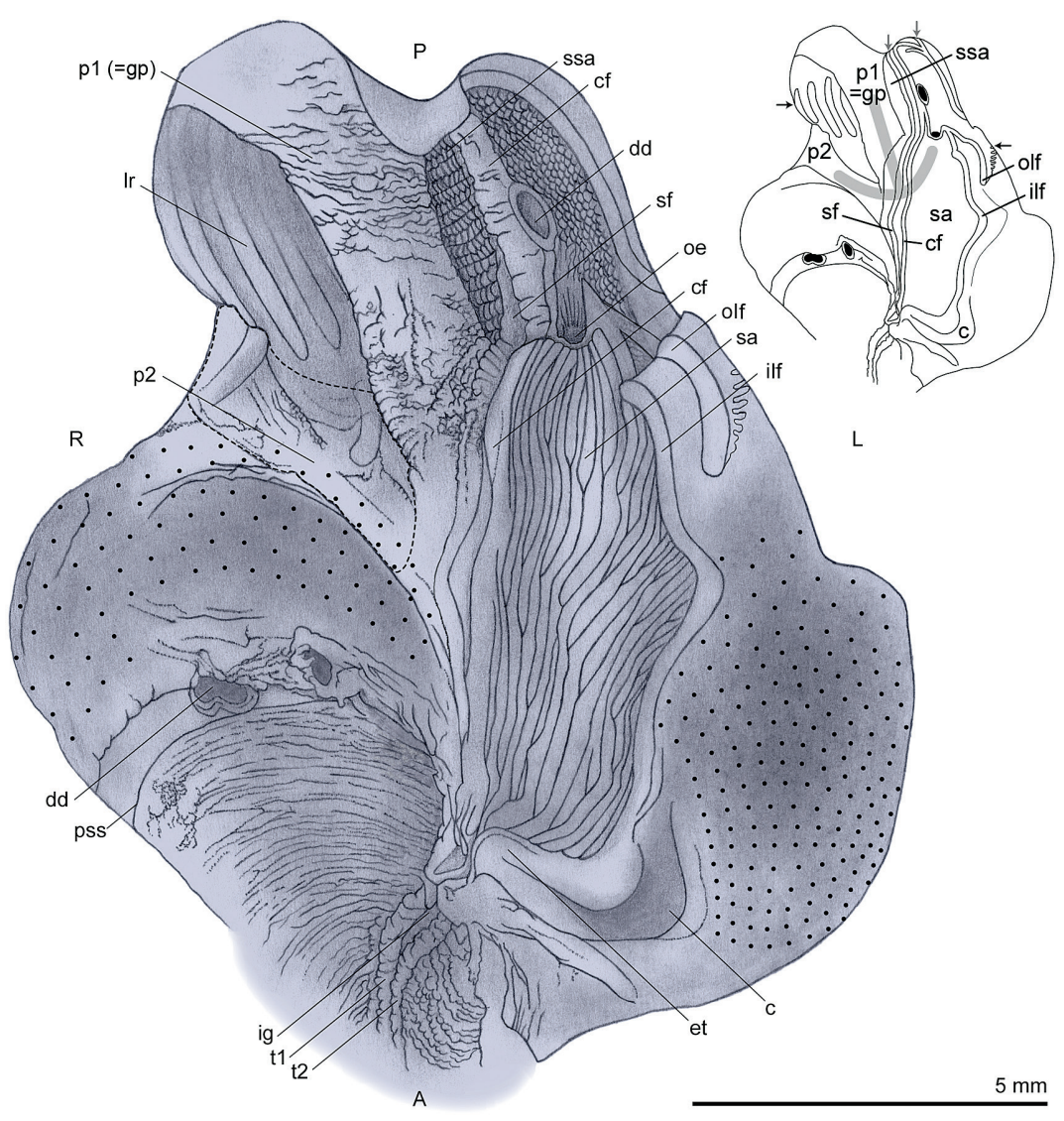

Fig. 8. Gastric chamber and proximal style sac, inset with a schematic representation. Evenly stippled area indicates cuticular lining; dashed line indicates the position of the gastric shield; $\mathrm{T}$-shaped ridge indicated in grey in inset; continuation of structures is indicated by small arrows in inset. Orientation: $\mathrm{A}=$ anterior; $\mathrm{L}=$ left $\mathrm{P}=$ posterior; $\mathrm{R}=$ right. Abbreviations: $\mathrm{c}=$ gastric pouch; $\mathrm{cf}=$ ciliated (or marginal) fold; $\mathrm{dd}=$ opening of digestive gland duct; et = expanded tip; $g \mathrm{p}=$ glandular pad; ig = intestinal groove; ilf = innermost left longitudinal fold; $1 \mathrm{r}=$ longitudinal ridge (continuation of finger-like ridges); oe = oesophagus; olf $=$ outermost left longitudinal fold; 1 1 = longitudinal part of the prominent T-shaped ridge (homologous to glandular pad); p2 $=$ transverse part of the T-shaped ridge; pss = posterior edge of the style sac region; $\mathrm{sa}=$ sorting area; $\mathrm{ssa}=\mathrm{sec}-$ ond sorting area with textured pad posteriorly; $\mathrm{sf}=$ smaller (outermost right longitudinal) fold; $\mathrm{t} 1$ = major typhlosole; $\mathrm{t} 2=$ minor typhlosole. 


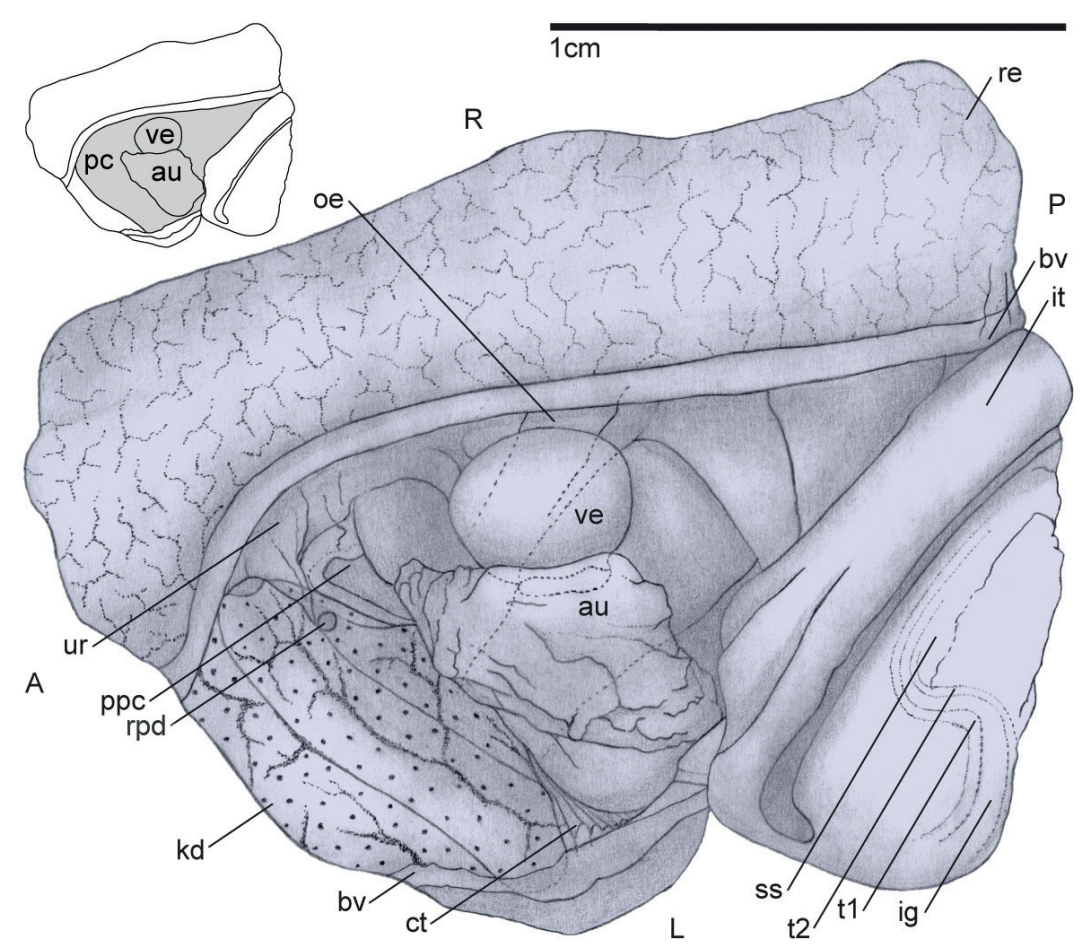

Fig. 9. Dorsal view of the pericardium, inset with a schematic representation. Orientation: $\mathrm{A}=$ anterior; $\mathrm{L}=$ left; $\mathrm{P}=$ posterior; $\mathrm{R}=$ right. Abbreviations: $\mathrm{au}=$ auricle; bv = blood vessel $; \mathrm{ct}=$ ctenidium; ig = intestinal groove; it = intestine; $\mathrm{kd}=$ kidney; $\mathrm{oe}=$ oesophagus; $\mathrm{pc}=$ pericardium; rpd = reno-pericardial duct; $\mathrm{ppc}=$ posterior margin of the pallial cavity; re = rectum; ss = style sac; $\mathrm{t} 1$ = major typhlosole; $\mathrm{t} 2$ = minor typhlosole; $\mathrm{ur}=$ ureter; ve $=$ ventricle. tric chamber into three regions. The longitudinal limb (= glandular pad) emerges from the right, posterior gastric chamber wall and forms a ridge along the floor to the right of the oesophageal opening. Roughly midway along the left side of the glandular pad, a single digestive gland duct opens to the gastric chamber floor. At the anterior end of the longitudinal limb, the transverse limb crosses the gastric chamber floor just in front of the oesophageal aperture and bears the gastric shield at right. A prominent sorting area is developed in the left gastric chamber floor and roof anterior to the oesophageal opening, and extends anteriorly to the intestinal groove. Two curving longitudinal folds in the gastric chamber roof border the left side of the sorting area, the outer left longitudinal fold more prominent than the inner. The inner left longitudinal fold emerges anteriorly in the vicinity of the proximal end of the minor typhlosole and has a prominently expanded tip; the outer fold has its anterior tip much farther back, at the level of the gastric shield. The two folds merge near the posterior end of the sorting area, forming a single fold that crosses from left to right just in front of the oesophageal opening, and continues posteriorly along the base of the glandular pad, passing above and to the right of the digestive gland duct. Two additional longitudinal folds border the sorting area at right (the ciliated or marginal fold and a smaller right longitudinal fold), and extend posteriorly from the vicinity of the proximal end of the major typhlosole. They are themselves bordered at the right by a smaller, narrower sorting area to the left of the gastric shield. This second sorting area persists posteriorly on the left side of the glandular pad to the rear wall of the gastric chamber. At the level of the digestive gland duct, another longitudinal fold emerges to the left of the duct in the gastric chamber floor. At the rear of the gastric chamber, this longitudinal fold and those on the left side of the glandular pad curve around the base of the glandular pad into the roof, merging and terminating at the right posterior end of the glandular pad, behind the gastric shield. Within the gastric chamber roof, from the prominent outer longitudinal fold to the left side of the main sorting area, a series of flattened finger-like ridges are elaborated. The ridges begin as small undulations at the anterior tip of the longitudinal fold, gradually elongating and broadening, spanning the roof and extending onto the gastric chamber floor behind the gastric shield at the right side of the glandular pad. The ridges stain lightly purple with toluidine blue, indicating they are glandular. Anteriorly, the transverse limb of the T-shaped ridge separates a deep, concave, cuticularized style sac pocket at the right (stippled re- 
gion, Fig. 8) that is interrupted ventrally at the left only by the sorting area and receives two ducts of the digestive gland below the lip of the style sac. At the left, anterior end of the main sorting area, the expanded tip of the weak inner left longitudinal fold delimits a shallow gastric pouch. The division between the gastric chamber and the style sac is demarcated by a constriction.

Digestive gland. The digestive gland is a large yellow, brown or greenish organ located in the visceral hump, usually occupying the $\sim 2.0-2.5$ most apical whorls, with its anterior $\sim 0.5$ whorl supporting the right aspect of the gastric chamber (Fig. 4). The digestive gland is incompletely divided into two lobes: a smaller anterior one, which borders the right wall of the gastric chamber, and a larger posterior one. The gland is drained by tubules that join the digestive gland ducts, which run along the columellar aspect of the visceral whorls. These ducts increase in size anteriorly, and open to the gastric chamber; one posteriorly, two anteriorly.

Style sac. The style sac is roughly 1.5 times the length of the gastric chamber and forms a voluminous undivided sac. It bears two ventral typhlosoles that traverse its length, bounding the intestinal groove. At the distal end of the style sac, the typhlosoles turn sharply to the left before continuing anteriorly through a $90^{\circ}$ angle (Fig. 9), with two shallow pyloric caecae elaborated between these curves. A crystalline style is absent.

Intestine. The intestine (Figs 4, 9) emerges from the anterior end of the style sac and curves $\sim 180^{\circ}$ to continue posteriorly; it overlies the pericardium and the right side of the style sac (Fig. 4). The typhlosoles of the style sac continue laterally into the intestine, with the major typholosole present for half the length of the intestine. The intestine continues posteriorly and its posterior limit coincides with the posterior wall of the pericardium; there the intestine turns back on itself to widen into the much larger and more thin-walled rectum.

Rectum. The rectum is thin-walled and semi-transparent so that the contents are easily visible externally. Posteriorly the rectum borders the right dorsal side of the pericardium (Fig. 9), and at the anterior end of the pericardium it enters the pallial cavity (= mantle cavity) to continue dorsally at the right side of the mantle roof, to the left of the ureter and the testis/brood pouch (Fig. 5). The rectum is surrounded by a layer of con- nective tissue that thickens ventrally and is penetrated by blood vessels, including a prominent vessel dorsally at the left side of the rectum, which comprise the rectal sinus. Anteriorly, at the mantle collar, the rectum becomes more muscular, and terminates in a free anal papilla (Fig. 5). In the anterior part of the rectum the feces are compacted into small, oval pellets.

\section{Reno-pericardial system}

Excretory system. The kidney is a compact, glandular mass of tubules with a small lumen that bounds the rear of the mantle cavity and encloses the region where the ctenidium and endostyle curve into the food groove (Figs 4,9). The kidney typically has a curved tetrahedral shape, but may be deformed somewhat by contraction at fixation. It is bordered at its dorso-lateral edges by two prominent blood vessels that converge at its pointed anterior tip; the vessel at right emerges from the rectal sinus (see the section on the rectum) and that at the left is the afferent branchial vessel (Fig. $4 \mathrm{~A}, \mathrm{~B}$ ). Another smaller vessel (the efferent vein of the nephridial gland sensu Andrews, 1979) along the posterior border of the kidney also connects to the posterior end of the afferent branchial vessel. The efferent branchial vein lies in close proximity to the afferent branchial vein at the posterior end of the kidney, and it is also connected to the auricle. A small nephropore opens dorsally at the right side, roughly at the posterior third of the kidney. It connects the main kidney chamber to a proximal expansion of the ureter lying between the kidney and the rectum. A small reno-pericardial duct at the right posterior side of the kidney (Fig. 9) lies in close proximity to the nephropore. The ureter continues anteriorly as a tall and narrow uninterrupted chamber between the pallial gonoduct and the rectum. As described above, the ureter opens anteriorly via the urinary pore (Fig. 5).

Heart and circulation. The heart lies antero-ventrally in the large, elongate pericardium, which is bordered by the rectum dorsally at the right, and by the intestine and the style sac dorsally at the left. The large auricle is somewhat anterior and to the left of the smaller, more muscular ventricle (Fig. 9). From the left, posterior aspect of the ventricle a short tube branches ventrally into two slender arteries, roughly equal in diameter, the cephalic aorta which runs anteriorly, and the visceral aorta. The visceral aorta branches almost immediately into two main branches; the left branch penetrates the viscera shortly behind the ventricle below the style sac, 

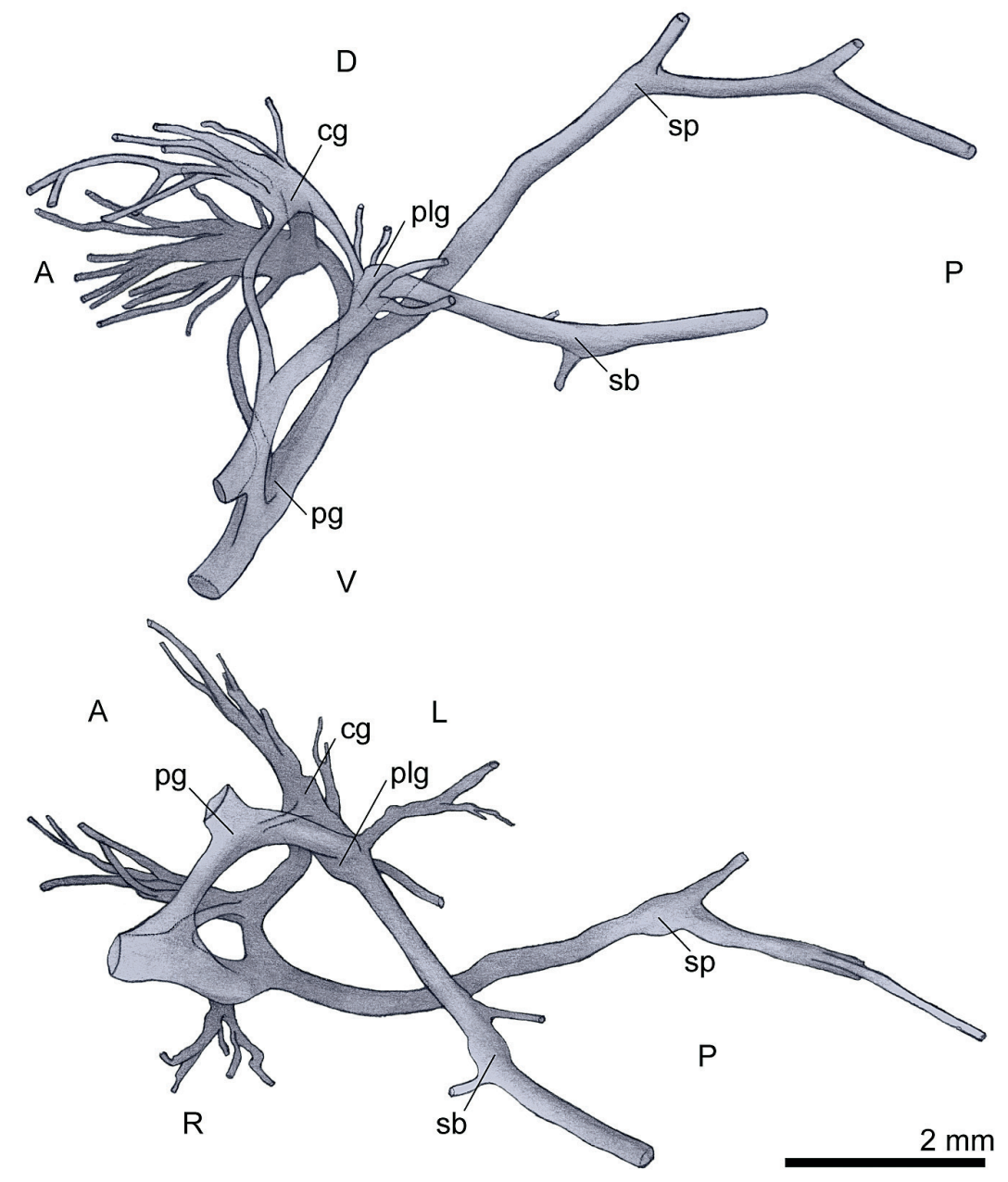

Fig. 10. Nerve ring in left lateral (above) and ventral view (below). $\mathrm{A}=$ anterior; $\mathrm{D}=$ dorsal; $\mathrm{L}=$ left; $\mathrm{P}=$ posterior; $\mathrm{R}=$ right; $\mathrm{V}=$ ventral. Abbreviations: $\mathrm{cg}=$ cerebral ganglion; $\mathrm{pg}=$ pedal ganglion (ventrally truncated); plg = pleural ganglion; $\mathrm{sb}=$ sub-oesophageal ganglion; $\mathrm{sp}$ = supra-oesophageal ganglion. whereas the right branch continues posteriorly along the floor of the pericardium alongside the posterior oesophagus.

\section{Nervous system}

The broad, epiathroid circum-oesophageal nerve ring lies obliquely just behind the buccal mass; it is rather symmetric and has widely separated ganglia (Fig. 10). The cerebral ganglia are especially well-developed and situated dorsally, just below the salivary glands on either side of the anterior oesophagus, behind the buccal mass; they possess well-defined labial lobes and are connected via a short, thick commissure. The buccal ganglia, are strongly rounded, well-defined in comparison to the other ganglia, and are situated on the postero-lateral sides of the buccal mass at the emergence of the anterior oesophagus (Fig. 6). The pedal ganglia are situated within the floor of the hemocoel, below the buccal apparatus; they are elongated (ventrally truncated in Fig. 10) and connected via a short commissure. Statocysts bearing numerous statoconia are laterally slightly separated from the pedal ganglia and slightly dorsal to the level defined by the pedal commissure. The pedal and cerebral ganglia are connected by long, slender cerebro-pedal connectives. The pleural ganglia lie posteriorly and ventrally to the cerebral ganglia; they are connected with the cerebral ganglia via short, thick connectives, and also to the pedal ganglia, via pleuro-pedal connectives that are shorter and thicker than the cerebro-pedal connectives; there is no pleural commissure, nor are there zygoses or a fusion of the pleural and the more posteriorly positioned sub- and supra-oesophageal ganglia. Long connectives emerge posteriorly from the pleural ganglia to join the supraand sub-oesophageal ganglia. The oesophageal ganglia 
lie alongside but slightly separated from the mid-oesophagus with the sub-oesophageal ganglion in a more anterior position than the supra-oesophageal ganglion. Long connectives from the supra-oesophageal and suboesophageal ganglia continue posteriorly towards the single visceral ganglion at the posterior end of the mantle cavity dorsal to the oesophagus.

The cerebral ganglia innervate the snout, eyes, tentacles, the buccal ganglia the buccal apparatus, the pedal ganglia the foot, the pleural ganglia the mantle, its edge and the mantle floor; the sub-oesophageal and supra-oesophageal ganglia innervate the columellar muscle and right mantle organs, and the ctenidium and osphradium, respectively; the single visceral ganglion innervates the viscera, including the kidney, the heart and the stomach.

\section{Reproductive system}

Bodies of females are usually more voluminous than those of males (Fig. 4), owing largely to the presence of the voluminous brood pouch, which occupies the same position as the more compact testis in males.
Male reproductive system. The male reproductive organs all lie within the pallial cavity (Fig. 11), although in some specimens the testis may extend somewhat posteriorly into the viscera. The testis is a large organ situated at the right side of the pallial cavity, bordered ventrally and on the right by the columellar muscle and by the ureter on the left. It is semi-lunar in shape with a wider, rounded dorsal side and a more pointed ventral one. The left side is more convex, whereas the right side is concave. The organ is compartmentalized and follicles drain to small tubules which converge towards canals which connect to the central, ventral region, where the vas deferens emerges. The vas deferens crosses just below the mantle floor towards the elevated area underneath the food groove at the left of the mantle cavity. There it opens to the base of the prostate, which continues anteriorly below the food groove for more than half the length of the mantle cavity, and deflects toward the right tentacle before reaching the head. In the right tentacle, the glandular penile duct continues below the central blood vessel and the tentacle nerve, both of which are more conspicuous and better developed in males than in females. Male gonopore at the tip of the tentacle.

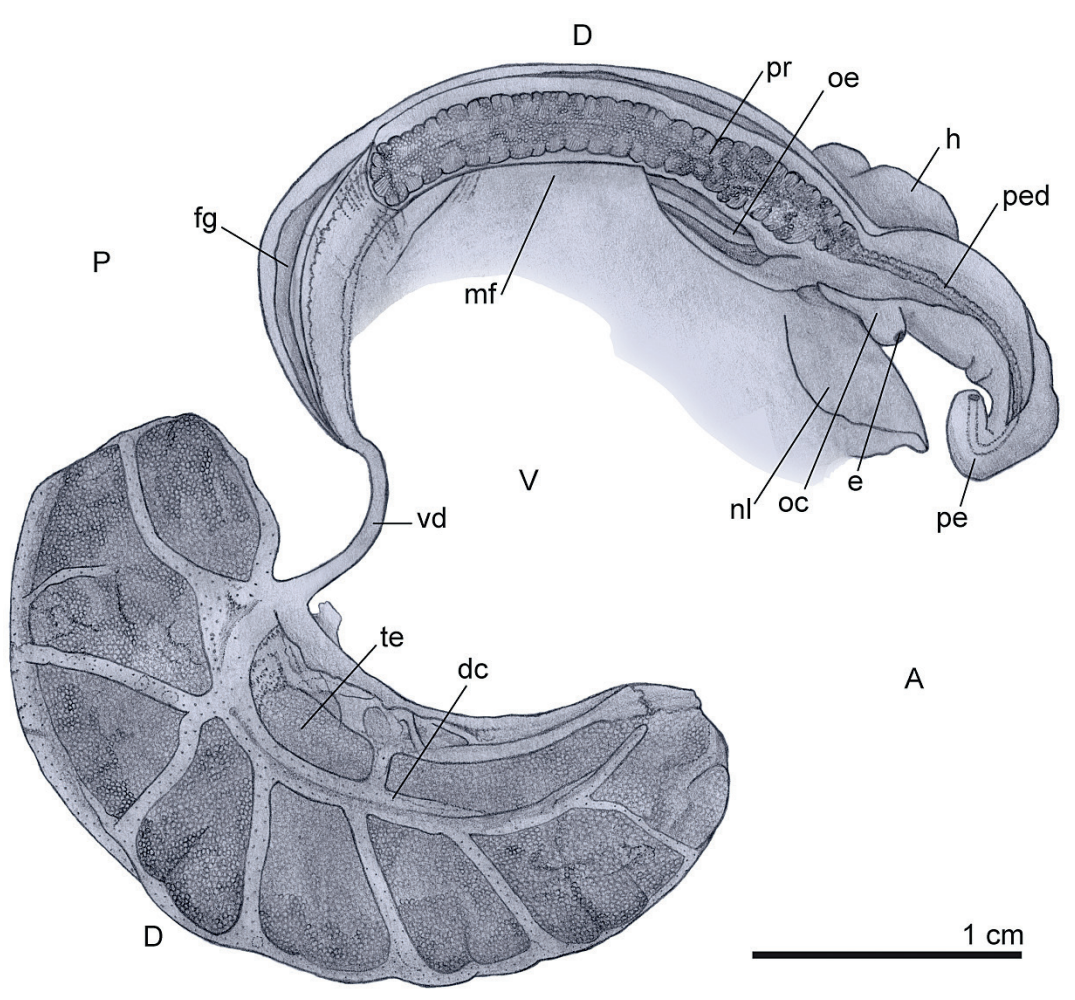

Fig. 11. Male reproductive anatomy. Testis is deflected and seen from the left; A = anterior; $\mathrm{D}=$ dorsal $\mathrm{P}=$ posterior; $\mathrm{V}=$ ventral. Abbreviations: $\mathrm{dc}=$ central drainage channel; e = eye; $\mathrm{fg}=$ food groove $\mathrm{h}=$ head $; \mathrm{mf}=$ mantle floor; $\mathrm{nl}=$ nuchal lobe; oe = oesophagus; oc = ocular peduncle; ped = penile duct; pe = penis; $\mathrm{pr}=$ prostate; te $=$ testis; vd = vas deferens. 


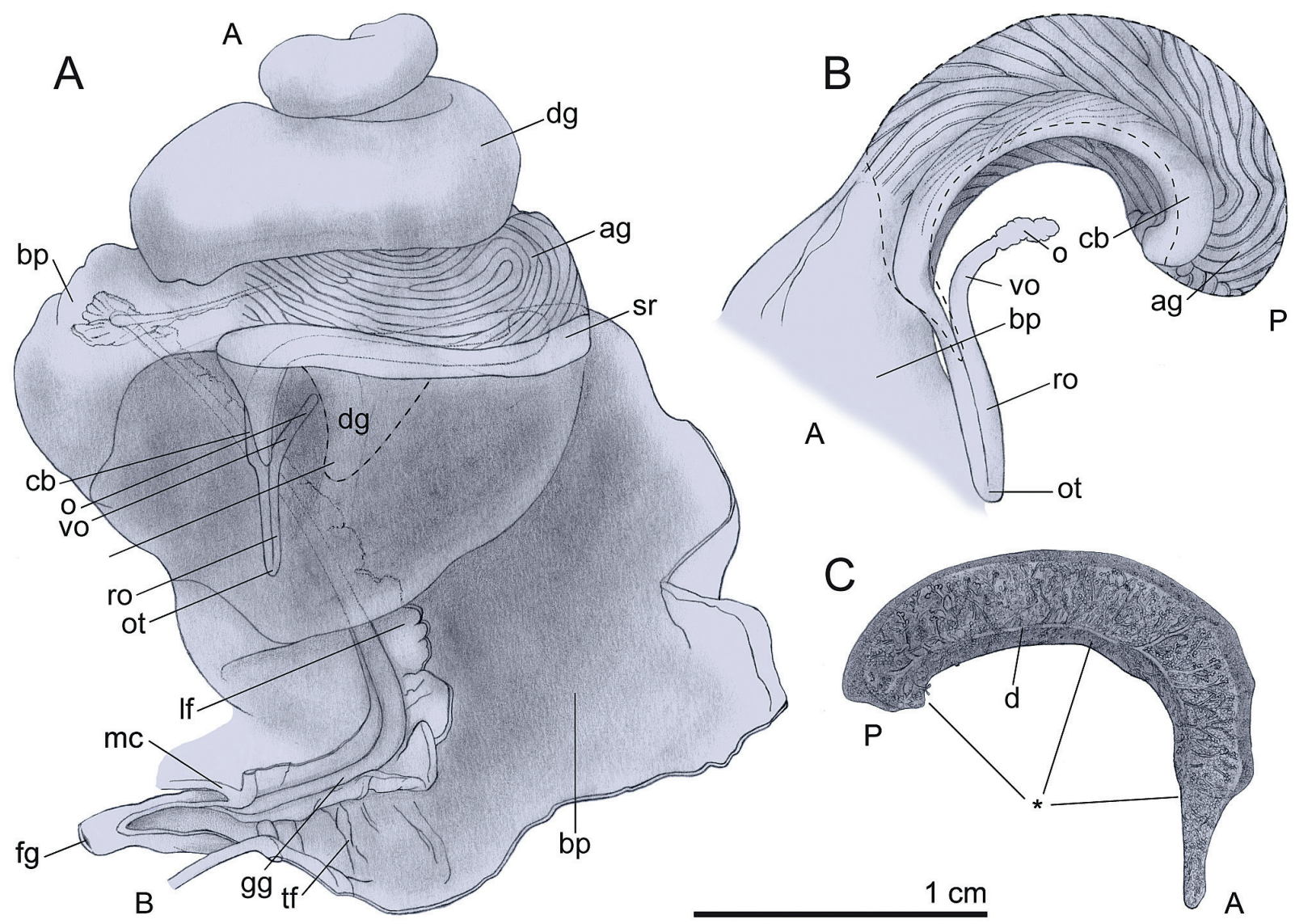

Fig. 12. Female reproductive anatomy. A) Overview; orientation: $\mathrm{A}=$ apical; $\mathrm{B}=$ basal; B) Oblique left-ventral view of albumen gland and copulatory bursa; position of seminal receptacle indicated by dashed line; $\mathrm{A}=$ anterior; $\mathrm{P}=$ posterior; $\mathrm{C}$ ) Seminal receptacle; $\mathrm{A}=$ anterior; $\mathrm{P}=$ posterior. Abbreviations: $\mathrm{ag}=$ albumen gland; $\mathrm{bp}=$ brood pouch; $\mathrm{cb}=$ copulatory bursa; $\mathrm{d}=\mathrm{duct}$ of seminal receptacle; $\mathrm{dg}=$ digestive gland; $\mathrm{fg}=$ female gonopore; $\mathrm{gg}=$ sperm groove; If = longitudinal fold; $\mathrm{mc}=$ mantle collar; $\mathrm{o}=\mathrm{ovary}$; ot = U-turn of renal oviduct; ro = renal oviduct; $\mathrm{sr}=$ seminal receptacle; vo = visceral oviduct; $\mathrm{tf}=$ transverse fold. $*$ indicates the part of the seminal receptacle that borders the copulatory bursa.

Female reproductive system. The reproductive organs of females span the pallial cavity and part of the visceral mass to the posterior end of the pericardium, and the junction of the intestine with the rectum (Fig. 12A). The ovary is very small, consisting of an elongate, lobate mass ventral to the anterior lobe of the digestive gland and along the columellar aspect of the pericardium (Fig. 12A). It borders the posterior oesophagus at the right, and extends posteriorly to the anterior ducts of the digestive gland. It constricts somewhat at its anterior end where it connects to the very short visceral oviduct. The visceral oviduct continues anteriorly as the renal oviduct, which forms a narrow, muscular, ciliated U-shaped tube at the ventral margin of the proximal brood pouch (Fig. 12B); a gono-pericardial duct is lacking. The narrower, proximal, descending limb of the renal oviduct is connected with a duct to a complexly branched seminal receptacle. The duct emerges at the antero-ventral margin of the seminal receptacle and continues posteriorly along the right ventral aspect of the receptacle (Fig. 12C, 13A). The small, darkly staining acini of the receptacle bear orientated sperm (Fig. 13F). The distal, ascending limb of the renal oviduct has a slightly wider diameter than the proximal limb, and it opens to the bulbous tip of the copulatory bursa, roughly at the level of the connection between the proximal limb and the seminal receptacle (Fig. 12B). The bursa is an elongate tube extending posteriorly flanked by the albumen gland and the seminal receptacle their entire length (Fig. 13B). The 

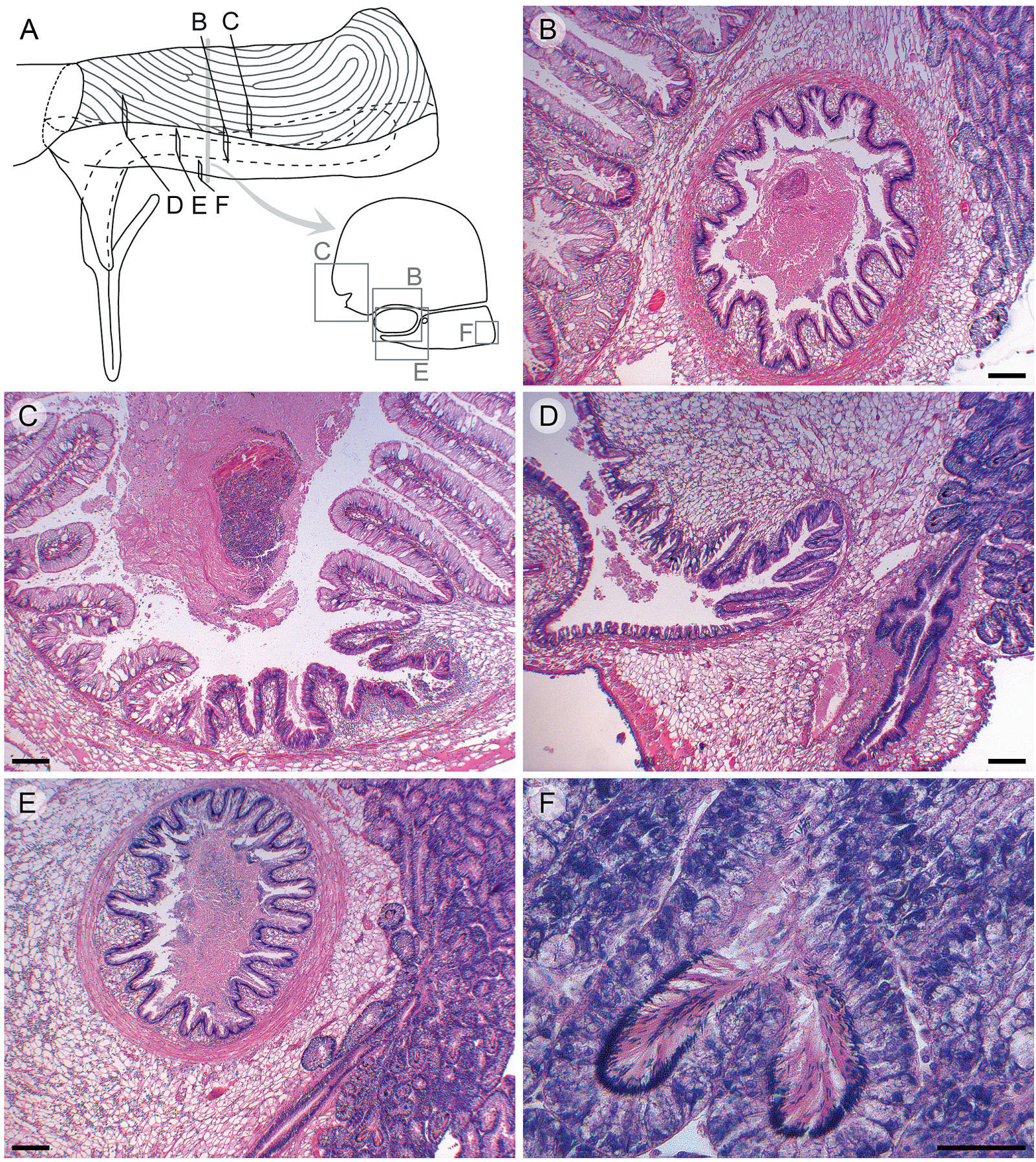

Fig. 13. Histology of female reproductive organs. A) Schematic drawing of the proximal reproductive organs with indications of the illustrated sections; the cross section is taken too far posteriorly to illustrate the position of section D; B) albumen gland (left), copulatory bursa with muscular wall embedded in connective tissue (center), and seminal receptacle (right); C) detail of ventral channel of the albumen gland with unorientated sperm; D) detail of ventral channel of albumen gland (left) and seminal receptacle (right) with receptacle duct at the lower right; E) copulatory bursa with unorientated sperm (left) and seminal receptacle with orientated sperm (right); F) orientated sperm in acini of the seminal receptacle. Scale bar $=50 \mu \mathrm{m}$ in B-E, $200 \mu \mathrm{m}$ in F. 
Table 2. Fecundity information for the seven female specimens that were subjected to anatomical study (indicated with their USNM numbers). Ea, Ed and $\mathrm{Ju}$ represent the number of freshly encapsulated, angulated eggs, more rounded developing eggs and juveniles, respectively.

\begin{tabular}{llrrrrr}
\hline Specimen & Ln (height) & Ea & Ed & Ju & Total & Fecundity \\
\hline 1296931 & 1.88 & 2 & 81 & 28 & 111 & 138.0 \\
1296932 & 1.74 & 14 & 28 & 12 & 54 & 59.0 \\
1296933 & 1.90 & 15 & 42 & 22 & 79 & 93.5 \\
1296939 & 1.93 & 0 & 115 & 22 & 137 & 159.0 \\
1296940 & 1.93 & 106 & 103 & 11 & 220 & 178.0 \\
1296941 & 1.76 & 42 & 55 & 9 & 106 & 94.0 \\
1296948 & 1.75 & 34 & 5 & 7 & 46 & 36.0 \\
\hline
\end{tabular}

bursa is surrounded by a conspicuous layer of circular muscles, and its lumen, roughly double the width of the distal renal oviduct, is lined by conspicuous longitudinal folds and contains copious quantities of unoriented eusperm. The distal bursa opens broadly to the posterior end of the voluminous albumen gland. The albumen gland is lined interiorly by tall, pendulous, glandular, longitudinal folds (Fig. 13C). A longitudinally grooved ventral channel, lined with abundant goblet cells (Fig. 13C), extends forward along the left floor of the albumen gland, and deepens anteriorly. Histological sections revealed the presence of unorientated eu- and parasperm in the vicinity of the channel. The large lumen of the albumen gland was observed to contain large quantities of flocculent material within which small, unencapsulated developing embryos were embedded. The albumen gland opens broadly at its anterior end to the voluminous, thin-walled brood pouch, which spans $\sim 1.5$ whorls, or $\sim 5 \times$ the length of the albumen gland. A tall, longitudinal fold extends the length of the brood pouch along its ventral floor; it is bilobed in cross section, with a tall, free-standing left arm and a smaller, thicker right arm under which passes the sperm groove, the anterior extension of the albumen gland ventral channel. Embryos become encapsulated in the posterior brood pouch, which is homologous to the capsule gland. Strings of capsule gland material form at the angular intersections of the freshly encapsulated eggs, but disappear anteriorly as the eggs mature. In smaller females the eggs in the brood pouch usually maintain a tightly packed formation (with angular margins), but these angulations disappear as the eggs mature, and in large females the eggs usually obtain a more chaotic arrangement. In large females the brood pouch usually contains many eggs, embryos and juveniles in advancing stages of development towards the anterior end (Fig. 4). Developing juveniles usually rupture the egg membrane before birth. Anteriorly, the pallial oviduct narrows and bears a set of transverse epithelial folds, before narrowing further and terminating near the mantle collar in the vagina. The vagina is a free hanging, muscular tube with a round terminal gonopore.

\section{Fecundity}

After examination of the contents of the brood pouch we developed the following fecundity index: $\mathrm{F}=0.5 *$ $\mathrm{Ea}+\mathrm{Ed}+2 * \mathrm{Ju}$ (with Ea, Ed and $\mathrm{Ju}$ the number of freshly encapsulated, angulated eggs, more rounded developing eggs and juveniles, respectively). This index accounts for the viability of specimens at different stages of development should they be released to the environment at their current stage, and also for the volume one specimen of each stage occupies in the brood pouch. The results indicate that fecundity increases markedly with female shell size and hence body volume (Table 2). For example, a female with a shell height of $\sim 5.75 \mathrm{~cm}$ has a fecundity index of $\sim 50$, but this increases to $\sim 140$ in a female with a shell height of $\sim 6.75 \mathrm{~cm}$.

\section{Morphometrics}

Upon subjecting the semi-landmark data to PCA, a scree plot indicates that the first 2 PCs explain significant proportions of the variation in the dataset $(\sim 77.8$ $\%$; Fig. 14) and should be retained. Two trends are clear from the morphometric data: first, small juveniles, subadults and adults occupy different portions of morphospace suggesting that important allometric changes occur during the growth of $C$. japonica, as was expected also from qualitative evaluation of the morphological variation displayed in Fig. 3. Second, males and females generally occupy the same region of morphospace. Most of the substantial allometric variation observed in $C$. japonica follows a linear function (Fig. 15A), indicating that allometric changes 


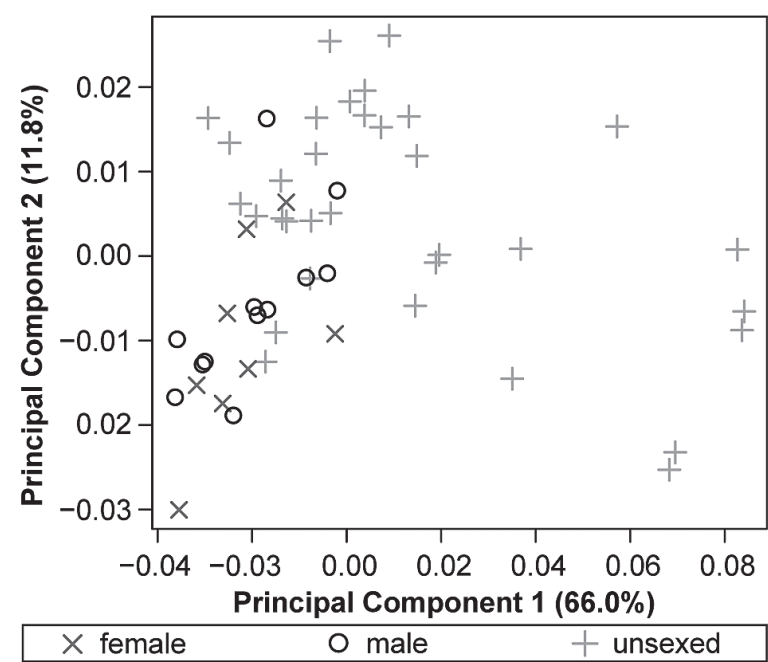

Fig. 14. PCA showing morphospace occupation (PC1 vs. PC2) of shells of Cipangopaludina japonica for male, female and unsexed specimens. The plot gives a first-order indication of allometric changes and sexual dimorphism in shell shape.

accumulate constantly through time. We observed an extremely good linear fit of PC1 with size $(r=-0.963$; $p<0.001)$. No net allometric changes between juveniles and adults occur along PC2 (Fig. 15B), but some intermediate life stages display allometric shape variation along PC2, i.e. mainly in specimens with a shell height of $2.7-4.5 \mathrm{~cm}$.

\section{Discussion}

In the discussion we relate our anatomical and morphological observations on $C$. japonica to others made for this taxon, for other viviparids and for other basal Architaenioglossa (Ampullarioidea Gray, 1824 and Cyclophoroidea Gray, 1847), to improve insights into the evolutionary ecology of the species and to establish a comparative framework for the study of viviparid natural history.

\section{Shell morphology}

Shells of $C$. japonica display several diagnostic features, for example, the adpressed whorls of the juvenile shells have a basal angulation and two spiral cords above the basal angulation (Figs 2-3), whereas the body whorls of adult specimens are much more inflated (Fig. 3). Juvenile shells obtained from the anteriormost brood pouch consistently display 4 whorls, with
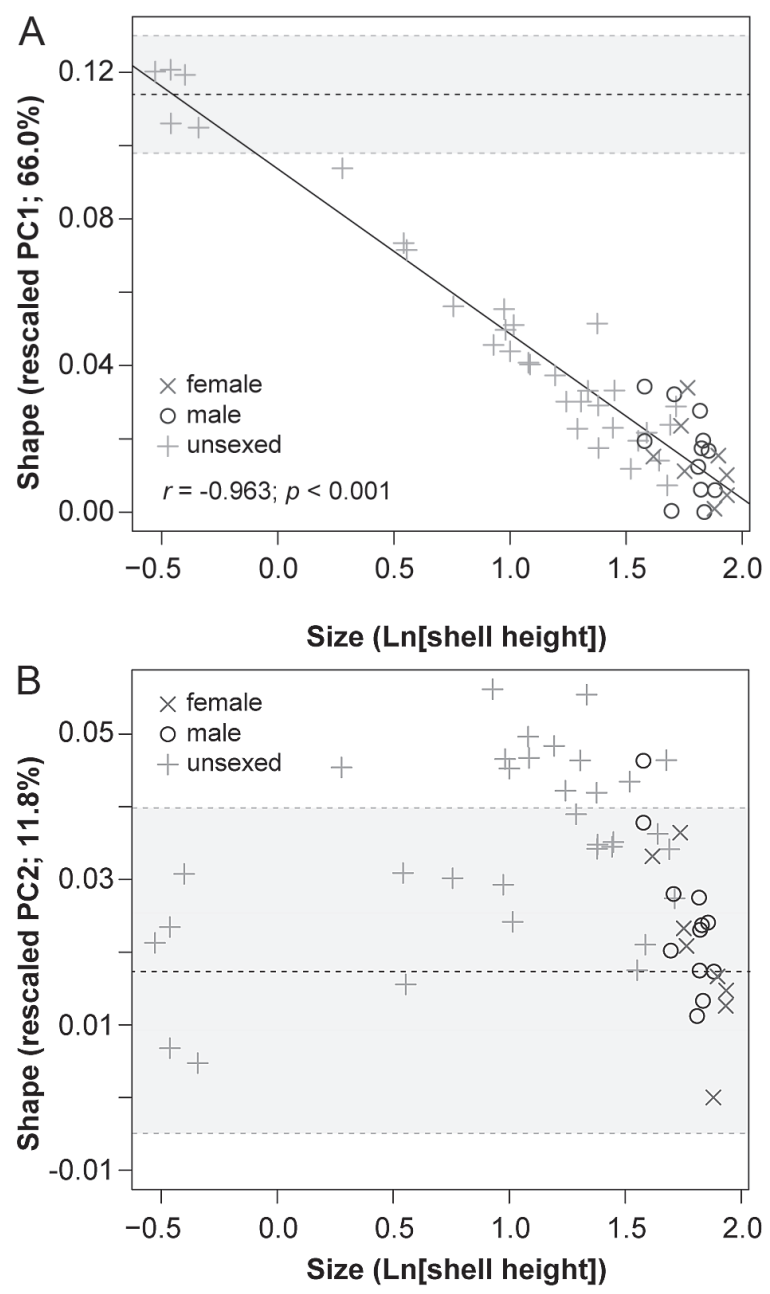

Fig. 15. Allometry in Cipangopaludina japonica. A) Shape change along PC1 versus shell height (regression line: $\mathrm{y}=$ $-0.044979 x+0.093648)$; B) Shape change along PC2 versus shell height. Central dotted line and shaded area indicate $95 \%$ probability intervals of no allometric change. Some specimens plot well outside this probability interval in both A and B, indicating multiple components of allometric change.

the protoconch elevated above the early teleoconch (von Martens, 1861; Reeve, 1863; Smith, 2000). Despite Smith's (2000) suggestion that $C$. chinensis has more spiral ridges than $C$. japonica, numerous ridges may be present in some $C$. japonica juveniles as well (e.g. Fig. 2B, C, E, F). Moreover, despite some variability in shell shape, as described earlier, the embryonic shells of unborn juveniles that we examined never displayed the high-spired morphology illustrated by Smith (2000; Fig. 5), neither in our samples from Virginia, nor in other records of $C$. japonica at the USNM 
from North America or Japan. The specimens most resembling Smith's are hatchlings from lot USNM 424320 (Fig. 2C).

\section{Anatomy}

Mantle cavity. The organization of organs in the mantle cavity of $C$. japonica (Fig. 5) compares well to that of other bellamyines (Chang, 1929), such as Filopaludina bengalensis (Lamarck, 1882) (Annandale and Sewell, 1921), Filopaludina sumatrensis (Dunker, 1852), Filopaludina (Siamopaludina) martensi (Frauenfeld, 1865) (Berry, 1974), Bellamya unicolor (Rohrbach, 1937), and also with that of other viviparids like Viviparus (Leydig, 1850; Simone, 2004) and Campelo$m a$ (Mattox, 1938). Ctenidial leaflets of viviparids appear to show consistent morphological differences that are possibly taxonomically diagnostic (Fig. 5) (Rao, 1925). One conspicuous difference between males and females of $C$.japonica is that the food groove is raised considerably more above the mantle floor in males, which relates to the presence of the large prostate below the mantle floor; the elevation of the food groove above the mantle floor in both sexes may assist somewhat in the functional separation of the inhalant (left) and exhalant (right) currents. Overall the mantle cavity of viviparids is organized somewhat differently than that of other basal Architaenioglossa. Unlike ampullariids (Berthold, 1991; Hayes et al., 2012), viviparids have no lung sac and respiration is performed primarily with the comparatively larger ctenidium. The main difference with the terrestrial cyclophoroids is that species of this superfamily lack a ctenidium and osphradium but have a highly vascularized mantle roof that acts as a lung (Andrews and Little, 1972; Haszprunar, 1988; Strong, 2003; Simone, 2004). The osphradium of viviparids is simple (Fig. 5) and differs considerably from that of ampullariids, which has an elliptical shape and bipectinate morphology (Berthold, 1991; Simone, 2004; Hayes et al., 2012). Additionally, unlike in other basal Architaenioglossa, the viviparid ctenidium is used for suspension feeding, and associated structures for such feeding, i.e. the endostyle and food groove (Fig. 5), which entrap filtered particles and deliver them to the mouth, are absent in other basal Architaenioglossa (Berthold, 1991; Simone, 2004; Hayes et al., 2012). Several authors have interpreted the endostyle of viviparids to be homologous to the hypobranchial gland of other gastropods (Annandale and Sewell, 1921; Rohrbach, 1937; Fretter and Graham, 1994), but the endostyle is bordered between the gill on the left and the afferent blood vessel on the right, whereas the hypobranchial gland is situated more to the right, along the midline of the mantle roof. Consequently, they do not share positional homology and therefore we consider this interpretation to be likely erroneous. Other basal architaenioglossans (ampullariids, but especially cyclophoroids) have better developed hypobranchial glands, which relates to the amphibious lifestyle of ampullariids and the terrestrial one of cyclophorids, as the gland would be involved in secretory and excretory functions during aestivation (Fretter and Graham, 1994). Viviparids, with their poorly developed hypobranchial glands, do not have such capabilities.

The mantle cavity of viviparids is comparatively longer than that of other basal architaenioglossans, where it usually occupies only 0.5-1.0 whorl (Simone, 2004). Several functional reasons exist for an elongated mantle cavity: the ctenidium is the sole respiratory organ in viviparids and it also serves for suspensionfeeding; moreover, the ovoviviparous mode of reproduction, with juveniles developing in a brood pouch may have caused selective pressures on the volume of the brood pouch and, hence, the dimensions of the mantle cavity.

Alimentary system. Overall the alimentary tract of $C$. japonica is relatively similar to that of other viviparids. To our knowledge in the first comparative study of bellamyine taxa, Rao (1925) claimed that no appreciable variation exists between bellamyines in alimentary organs, the kidney and the central nervous system, and this has been re-iterated by a number of other authors for specific parts of these organ systems. However, in what follows we will illustrate that this view cannot be maintained after in-depth study of these organs in C. japonica and comparison of our findings to published information for other viviparids.

According to some previous authors (Annandale and Sewell, 1921; Rohrbach, 1937) the radula is consistently shaped among Viviparidae, and is of limited systematic utility, but others have used it to delimit genera (Clench, 1962) or even to trace species relationships (Falniowski et al., 1996). The radula of C. japonica is similar to that of $F$. bengalensis (Annandale and Sewell, 1921; Starmühlner, 1983) but it bears fewer denticles on each tooth type, there is a greater differentiation in denticle size in C. japonica, and additionally the rachidian has conspicuous gaps adjacent to the central cusp (Fig. 7). It also resembles the radula of Trochotaia (Du et al., 2011), but the very small cusps 
adjacent to the central rachidian cusp, and at the inner side of the central cusp of the lateral tooth, give the radula of $C$. japonica a distinctive appearance. Additionally, we observed marked differences in the width of the rachidian, its overall morphology (triangular or more bluntly triangular), the width of the central cusp, the size of central cusp in comparison to other cusps, etc. between species of Viviparus (e.g. Baker, 1928; Falniowski et al., 1996; Simone, 2004), and even more substantial differences upon comparing radulae of Campeloma, Cipangopaludina, Larina, Lioplax, Notopala, Taia, Tulotoma and Viviparus (Annandale and Rao, 1925; Clench, 1962; Simone, 2004). Hence, we anticipate that detailed SEM studies may reveal important and consistent differences in radula morphology between viviparid genera. Overall, the radulae of viviparids are more delicate than those of other basal Architaenioglossa, and viviparid jaws are comparatively smaller to those of ampullariids (Berthold, 1991; Simone, 2004), which reflects the suspension and deposit feeding strategy of viviparids.

In $C$. japonica the salivary glands are large and integrated into a single, large glandular mass, that cannot be separated into right and left lobes (Fig. 6), which likewise is the case for $F$. bengalensis (Annandale and Sewell, 1921; Starmühlner, 1983), and the unidentified Chinese viviparids examined by Chang (1929). Several other viviparids, such as Campeloma subsolidum (Anthony, 1844) (junior synonym of C. crassula Rafinesque, 1819), Viviparus viviparus, Viviparus acerosus (Bourguignat, 1862), Viviparus contectus (Millet, 1813), Neothauma tanganyikense (Smith, 1880), Notopala ampullaroides (Reeve, 1863), Notopala essingtonensis (Frauenfeld, 1862) and Larina strangei Adams, 1854 have separate left and right salivary glands (Speyer, 1855; Call, 1888; Moore, 1901; Simone, 2004), and in Notopala and Larina the salivary glands are tubular, rather than massive (Simone, 2004). Hence, substantial variation is observed in salivary gland morphology, although salivary gland ducts invariably pass through the nerve ring. Most other basal Architaenioglossa have separate, paired salivary glands (Berthold, 1991; Simone, 2004; Hayes et al., 2012), but exceptions exist, e.g. Incidostoma Morrison, 1942 (Simone, 2004).

Detailed accounts on buccal musculature consistent with our observations on $C$. japonica are provided by Fretter and Graham (1994; p. 185) and Simone (2004). The oesophagus of $C$. japonica is a simple tube without expansions or glandular elaborations (Fig. 6), much like that of other studied viviparids and in contrast to that of other basal architaenioglossans, where glandular pouches and/or a mid-oesophageal crop are present (Strong, 2003; Simone, 2004; Hayes et al., 2012). In $C$. japonica, the posterior oesophagus opens to the left gastric chamber floor at the level of the posterior end of the gastric shield (Fig. 8). This organisation is more similar to basal sorbeoconchans (Strong, 2003; Strong, 2011) than to other architaenioglossans, including some viviparids. For example, in F. bengalensis (Annandale and Sewell, 1921), and seemingly also Viviparus acerosus (Simone, 2004), the oesophagus apparently inserts in the posterior, left region of the gastric chamber, in a position somewhat similar to that in ampullarids (Berthold, 1991; Hayes et al., 2012). In cyclophorids the oesophagus opens to a long ledge that starts centrally and continues to the posterior end of the gastric chamber (Strong, 2003; Simone, 2004).

The gastric chamber has not received sufficiently detailed descriptions to enable comparisons across bellamyines. The only in-depth description of the gastric chamber of another bellamyine ( $F$. bengalensis) was provided by Annandale and Sewell (1921), and comparison to that of $C$. japonica (Fig. 8) suggests great similarity in organization. Somewhat greater differences exist for V. viviparus (Leydig, 1850). Compared to ampullariids, the stomach walls are thinner and less muscular in viviparids and the gastric shield is better developed (Berthold, 1991; Simone, 2004; Hayes et al., 2012). The longitudinal limb of the Tshaped ridge in the gastric chamber of $C$. japonica (Fig. 8) is hypothesized to be homologous to the glandular pad of basal sorbeoconchans, and the inner longitudinal fold bordering the prominent sorting area at right may be homologous to the (ciliated) marginal fold (Strong, 2011).

A style sac was considered absent in ampullariids, cyclophorids and viviparids by Simone $(2004 ; 2011)$, based on the notion that recognition of the style sac is contingent upon the presence of the crystalline style. We disagree with this viewpoint (Strong, 2003). The homologue of the style sac region, with its characteristic typhlosoles, has been consistently recognized in ampullarids (e.g. Berthold, 1991; Strong, 2003; Hayes et al., 2012). Like in the few other viviparids analyzed in detail (e.g. F. bengalensis) (Annandale and Sewell, 1921), the style sac of $C$. japonica communicates broadly with the intestinal groove and lacks a crystalline style. The intestine lies close to the kidney and pericardium, but dorsal to the pericardium in $C$. japonica (Fig. 9), like in F. bengalensis (Annandale and Sewell, 1921) and Trochotaia pyramidella (Du et al., 
2011), not inside the pericardium as reported for Lari$n a$ and Notopala (Simone, 2004: 427). Elaborate intestinal loops, as observed in ampullariids, are not present in C.japonica nor in other studied viviparids ( $\mathrm{Si}$ mone, 2004), and the intestine does not pass through the kidney as it does in ampullariids (Berthold, 1991; Simone, 2004; Hayes et al., 2012). Although seemingly a muscular tube, the intestine of $C$. japonica was difficult to separate from the surrounding connective tissue and the glandular periphery suggesting that it functions in resorption, as confirmed histologically by Chang (1929) in other viviparids. The position of the intestine and rectum close to a major blood vessel (Fig. 4B, 4D, 9), which branches off over the rectum in $C$. japonica, and also in other viviparids (Andrews, 1979), additionally supports the hypothesis that intestine and rectum are the main areas of nutrient resorption.

Reno-pericardial system. The kidney of $C$. japonica (Fig. 4B, 9) compares well with those described for other viviparids (Perrier, 1889; Annandale and Sewell, 1921; Chang, 1929), and has been considered to represent an enlarged (hypertrophied) nephridial gland (Andrews, 1988; Fretter and Graham, 1994). However, Cyclophoroidea and Ampullariidae lack a nephridial gland (Andrews, 1988; Ponder and Lindberg, 1997; Strong, 2003), and, consequently, homology of the viviparid renal organ to the nephridial gland is doubtful. Cyclophorids have a pallial renal organ that is a 'kidney of accumulation', although some apparently have filtration chambers (Andrews and Little, 1972; Andrews, 1988), whereas ampullariids have a highly modified renal organ, with anterior and posterior chambers (Andrews, 1988; Berthold, 1991; Ponder and Lindberg, 1997; Hayes et al., 2012). Simone (2004) reported the presence of a posterior kidney chamber in viviparids, presumably by assuming structural identity with ampullariids, but to our knowledge this has not been reported in any other viviparid, and we also found it to be lacking in C.japonica.

Overall kidney shape has recently been considered to be systematically informative in viviparids ( $\mathrm{Lu}$ et $a l ., 2014$ ), but a detailed comparative framework, e.g. as to the relative positions of the reno-pericardial duct and the nephropore remains largely lacking. The renopericardial duct allows the passage of primary urine from the pericardium to the kidney; the nephropore the passage of secondary urine from the main kidney chamber to a proximal expansion of the ureter (Fretter and Graham, 1994). In viviparids, the nephropore lies within a tubular, closed ureter, whereas other basal Ar- chitaenioglossa have an open urinary gutter (Andrews and Little, 1972; Simone, 2004). In viviparids the kidney is generally smaller and the pericardium greatly enlarged compared to those of ampullariids (Hayes et al., 2012).

The voluminous pericardium forms a storage chamber for primary urine before it is passed to the kidney for further modification; formation of primary urine is described by Andrews (1976) and Fretter and Graham (1994). In viviparids, the auricle and ventricle lie more along a left-right axis whereas the arrangement in ampullariids is along a more ventral-dorsal axis, although much variation exists (Berthold, 1991: 40). In all basal architenioglossans the visceral aorta bifurcates in the proximity of the heart, but ampullariids possess (consistently, but to varying degrees) an ampulla in the anterior aorta in proximity to the heart (Berthold, 1991; Hayes et al., 2012), which is lacking in viviparids.

Nervous system. The ganglia of the nerve ring are widely separated in C.japonica (Fig. 10), and are not as developed as the more strongly rounded ganglia of higher caenogastropods, or even of the lioplacine genus Campeloma (Savage, 1938). Poor delimitation of the pedal and pleural ganglia from their connectives and commissures in viviparids (Leydig, 1850; Bouvier, 1887; Annandale and Sewell, 1921; Rao, 1925; Fretter and Graham, 1994; Simone, 2004) has caused some difficulties for the characterization of the nerve ring (Simone, 2004). However, at least in C. japonica, ganglia can be delimited reasonably well. Nevertheless, the difficulties in delimiting ganglia aside, some apparent variability in nerve ring morphology among viviparids has contributed to difficulty in classifying the nerve ring. For example, Haszprunar (1988) suggested the nerve ring of viviparids to be hypoathroid on the left side and epiathroid on the right side, but this is not supported by his original sources: Bouvier (1887: 64, figs. 15, 16) and Starmühlner (1983: 180) indicated that the length of the connectives between the cerebral and pleural ganglia was somewhat asymmetric, but that the pleural and cerebral ganglia were situated in close proximity. Annandale and Sewell (1921: 238239) described the nerve ring to be dystenoid on the left side and epiathroid on the right. Other studies on viviparids also display some asymmetry in nerve ring organization (Moore, 1901; Rao, 1925), but much more limited than that suggested by Haszprunar (1988), and none would qualify as hypoathroid. Fretter and Graham (1994: 278, fig. 153B) claim the nerve ring of Viviparus to be dystenoid, but their figure illustrates 
the pleural and pedal ganglia to be much closer to one another than Bouvier (1887) suggested for Viviparus and than we observed in C.japonica. These viviparids, and several other bellamyines (Rao, 1925), have nerve rings that resemble epiathroid conditions better (Fretter and Graham, 1994: 279, fig 154A).

The nerve ring of $C$. japonica is rather symmetrical (Fig. 10), with a somewhat shorter cerebral commissure compared to that in Viviparus species (e.g. Moore, 1901), although the length of the cerebral commissure in C. japonica is similar to that displayed for Viviparus viviparus by Bouvier (1887). However, the cerebral ganglia of $C$. japonica are not as close to one another as in Notopala (Simone, 2004), Neothauma (Moore, 1901), Taia (Rao, 1925) or Campeloma (Savage, 1938). The elongate pedal ganglia of $C$. japonica have a relatively long commissure in comparison to Viviparus and Campeloma, which overall resembles that of Notopala (Simone, 2004). Neothauma has been described to have a zygoneurous connection on the left side (Moore, 1901), but most viviparids do not appear to display zygoses. Either the morphology of the nerve ring in viviparids is somewhat plastic, as sometimes large interspecific differences are observed within a genus (e.g. compare species of Taia in Rao, 1925), or the nerve ring may contain more systematic information in viviparids at the generic level than is currently recognized.

As in other viviparids (Bouvier, 1887; Moore, 1901; Annandale and Sewell, 1921; Chang, 1929; Savage, 1938; Simone, 2004), the nerve ring is positioned posterior to the buccal mass in $C$. japonica (Fig. 6), which compares well to the positon of the nerve ring in basal sorbeoconchans, but not to that of ampullariids and cyclophorids, in which the nerve ring overlies the buccal mass (Strong, 2003; Simone, 2004). The position of the pleural ganglia near the cerebral ganglia in viviparids (epiathroid or dystenoid) more closely resembles the conditions in basal sorbeoconchans than those in ampullariids and cyclophorids, where the pleural ganglia are near the pedal ganglia (hypoathroid) (Haszprunar, 1988; Berthold, 1991; Strong, 2003; Simone, 2004). As a result of differences in the position of the nerve ring to the buccal mass, the buccal ganglia lie posterior to the nerve ring (Berthold, 1991; Strong, 2003) and often dorsally along the medial line (Berthold, 1991; Simone, 2004) in ampullariids and cyclophorids, whereas they are consistently anterior to the nerve ring and in a lateral position in viviparids (Fig. 6), which again is more similar to the conditions in basal sorbeoconchans. Furthermore, a fusion be- tween the pleural and the sub/supraoesophageal ganglia is common in ampullariids (Berthold, 1991; Simone, 2004), but not in viviparids, and also the pleural commissure of ampullariids is lacking in viviparids. Whereas only minor differences in the anatomy of the nervous system have been observed in ampullariids (Berthold, 1991), major differences are observed in viviparids, but additional modern comparative work is required to verify these observations.

Reproductive system. Like most viviparids, $C$. japoni$\mathrm{ca}$ is dioecious (Fig. 4), although populations of Campeloma rufum and other Campeloma species are known to reproduce parthenogenetically (Mattox, 1938; Johnson and Bragg, 1999), and there is a likely erroneous report that Viviparus angularis may be hermaphroditic (Vail, 1977). In general, the reproductive anatomy of viviparids is described with insufficient detail, and with conflicting interpretations of homology and functional morphology, leading to limited reliability of reproductive characters in systematics. Recent comparative work on other caenogastropods (Ponder and Lindberg, 1997; Strong, 2003; Simone, 2004; Simone, 2011), in combination with detailed histological examination of male and female reproductive organs in C. japonica, allow us to begin constructing a robust and consistent comparative framework for viviparid reproductive anatomy. Our histological investigations confirmed previous descriptions of the male reproductive tract, but that of the female requires more comparative study. However, much variation exists that could be systematically informative.

Major differences in male reproductive anatomy are evident between C. japonica (Fig. 5, 11) and other bellamyines in comparison to other viviparid subfamilies. As described above, the testis lies in the pallial region in bellamyines, and may extend somewhat into the visceral mass, but does not occupy the apical whorls in close association with the digestive gland as in the other subfamilies (Rohrbach, 1937). In Viviparus the testis are divided into anterior and posterior parts (von Erlanger, 1891; Vail, 1977), both of which occur in proximity to the digestive gland, but with the anterior part near the anterior margin of the digestive gland. This division likely allowed the evolution of the pallial arrangement of the testis in Bellamyinae through anterior migration of the anterior part and regression of the posterior part. The plausibility of this scenario is confirmed by Idiopoma dissimilis, which has the testis in an intermediate arrangement: it lies mainly in the mantle cavity, but with a posterior part that occupies 
the right aspect of the pericardium and is posteriorly adjacent to the anterior digestive gland (Annandale and Sewell, 1921). In C. japonica, the region of the body occupied by the albumen gland, copulatory bursa and seminal receptacle in females, is occupied by connective tissue in males (Fig. 4). The position of the testis greatly affects the length and shape of the vas deferens (Vail, 1977; Smith, 2000), which joins the prostate embedded below the mantle floor (von Erlanger, 1891; Rohrbach, 1937; Vail, 1977). Variation in the length and appearance of the prostate is evident, from equaling the mantle cavity in length in Viviparus and to a lesser extent in Lioplax, to less than half that length in Campeloma; from highly convoluted in Campeloma and Lioplax to a straight, non-convoluted duct in Viviparus (Vail, 1977). In bellamyines the prostate is a straight, glandular organ surrounded by a layer of connective tissue (Fig. 11) (Annandale and Sewell, 1921; Rohrbach, 1937; Berry, 1974). The right tentacle is modified into a penis in males of all subfamilies, but $C$. japonica lacks a tentacular hook, which is also absent in other Bellamyinae (Annandale and Sewell, 1921; Rohrbach, 1937), and in Campeloma geniculum (Conrad, 1834), but is present in Lioplax pilsbryi Walker, 1905 and Viviparus georgianus (Lea, 1834) (Vail, 1977). The male gonopore occurs invariably at the tentacular tip, but in $C$. japonica and other bellamyines no special cavity exists for the retraction of the right cephalic tentacle tip, as in Viviparus (Baker, 1928; Rohrbach, 1937; Vail, 1977). Simone (2004: 489-490, figs. 317, 321) appears to have mistaken the testis for the prostate and considered the prostate to be an ejaculatory duct.

As mentioned, confusion surrounding female reproductive anatomy in viviparids stems from the absence of comparative studies in a modern, synthetic, functional morphologic framework with hypotheses of homology that are consistent with what is known for other caenogastropods. A clear example is the organ indicated here as copulatory bursa: some have indicated this organ to be a bursa (Neumann, 1928; Van der Schalie, 1965), whereas others have hypothesized it to be an 'egg shell gland' (Mattox, 1938; Anderson, 1966), a 'seminal receptacle' (e.g. Baudelot, 1863; von Erlanger, 1891; Rohrbach, 1937; Berry, 1974; Vail, 1977), or simply an 'oviduct' (Chang, 1929). Similarly, the organ here identified as the seminal receptacle has been considered to be an 'albumen gland' (Baudelot, 1863; von Erlanger, 1891; Annandale and Sewell, 1921; Neumann, 1928; Rohrbach, 1937; Mattox, 1938; Berry, 1974; Vail, 1977), an 'ovary' (Chang, 1929) or has not been named (Van der Schalie, 1965; Anderson, 1966). Histological work on C. japonica (Fig. 13) confirmed the findings of Vail (1977) on other viviparids that sperm is present in both of these organs, unorientated in the first (bursa) and orientated in the second (seminal receptacle). Ankel (1925) indicated that eusperm may survive for up to 11 months in the seminal receptacle (as an 'albumen gland') but for only $~ 5$ months in the bursa (as a 'receptaculum') of Viviparus. These findings, combined with our observations on C. japonica allow us to refine our understanding of viviparid female reproductive anatomy.

Reproductive organs in female $C$. japonica extend somewhat into the visceral mass (Fig. 12), but occupy the columellar and right walls of the large pericardium rather than occurring more posteriorly in association with the digestive gland, as in Viviparinae and Lioplacinae (Vail, 1977). The position of the ovary in females of $C$. japonica (Fig. 12) differs from that described in other bellamyines, which more resemble Viviparinae and Lioplacinae in this respect (Annandale and Sewell, 1921; Rohrbach, 1937). In C. japonica (Fig. 12B), F. (S.) martensi and F. sumatrensis the ovary is very small and, for reasons that are obscure, much smaller than the seminal receptacle (Vail, 1977). In general, oocytes of viviparids are small $(<100 \mu \mathrm{m}$; Berry, 1974; Vail, 1978). The delimitation of the visceral, renal and pallial oviduct in $C$. japonica is somewhat uncertain at present, but most likely the seminal receptacle and the copulatory bursa represent elaborations of the renal oviduct, indicating that the visceral oviduct is the short connection between the ovary and the seminal receptacle duct, and that the pallial oviduct consists only of the albumen gland and the brood pouch, with its posterior region homologous to the capsule gland. This delimitation of the pallial oviduct has been proposed before in viviparous species (Fretter and Graham, 1994: 347) and is consistent with that in other caenogastropods. Consequently, unlike as reported by Vail (1977), the pallial oviduct invades the visceral mass in all viviparid subfamilies.

The seminal receptacle is consistently tubular in viviparids, but the duct apparently continues within the organ for $\sim 2 / 3$ of its length in Viviparus viviparus (Neumann, 1928), whereas it almost reaches the posterior margin in C. japonica (Fig. 12C). The tubular nature increases the surface to volume ratio and hence increases the storing capacity of orientated sperm. Beyond the histological evidence that the organ functions in sperm storage, a number of other considerations exclude the function of the seminal receptacle as 
an 'albumen gland'. First, in all other caenogastropods the albumen glands form glandular lamellae through which the eggs pass; they do not supply eggs with albumen via a single duct. Second, and perhaps more significantly, small, unencapsulated embryos were found exclusively more distally in the structure identified here as the albumen gland embedded in flocculent albumen. In bellamyines, the copulatory bursa is a long tube, not a short sac-like widening of the posterior end of the pallial oviduct as in Viviparinae and Lioplacinae (Neumann, 1928; Rohrbach, 1937; Vail, 1977: 538, figs. 40, 42). The albumen gland of C. japonica compares well with that of $F$. bengalensis (Annandale and Sewell, 1921). Whether sperm ingestion occurs at any part in the female reproductive tract is still uncertain.

The modification of the distal pallial oviduct into a voluminous brood pouch is unique for viviparids within basal Architaenioglossa (Strong, 2003; Simone, 2004). Juveniles typically hatch from eggs before being expelled from the mother (Crabb, 1929). This strategy is better termed 'ovoviviparous' rather than 'viviparous' (e.g. Prashad, 1928; Van der Schalie, 1936), wherein the embryo is intimately connected to the mother and obtains continuous nourishment from her (e.g. as in mammals), a strategy that has not been substantiated in mollusks (Ben-Ami and Hodgson, 2005). In $C$. japonica eggs usually seem to hatch in the pallial oviduct (Fig. 4B) and only juveniles are expelled to the environment, although it is possible that the release of unhatched viviparid eggs could result in viable juveniles, and Viviparus georgianus females were observed to frequently lay eggs (Crabb, 1929). The separation between laying eggs and giving birth appears to be subject to behavioral changes. Stressed females of several bellamyines appear prone to releasing juveniles and eggs, perhaps because chances of survival are greater in the wild than in a deceased mother.

Neumann (1928) suggested that the comparatively larger brood pouch of Viviparus may relate to its Palaearctic distribution, with winters being unfavorable for reproduction. However, C. japonica and some other Bellamyinae which occur at higher latitudes likewise cease reproduction during winters (Stańczykowska et al., 1971), whereas subtropical and tropical viviparids display seasonal variation in reproductive activity (Berry, 1974; Vail, 1978). More comparative work within and between taxa at different times of the year is required to fully understand viviparid reproductive strategies.

\section{Functional morphology and evolutionary ecology}

Food uptake. Many viviparids are filter feeders, and obtain nutrients by filtering water over the gill (e.g. Prashad, 1928). Examination of the pallial cavity, with its conspicuous food groove, suggests $C$. japonica to be a filter feeder as well, but study of the contents of the intestinal tract indicates that the species is also a deposit feeder. Such behavior has been observed in Filopaludina bengalensis and C. chinensis previously (Annandale and Sewell, 1921; Stańczykowska et al., 1972; Plinski et al., 1978), and in other viviparids (Aldridge, 1983). In our specimens many relatively large wood pellets were ingested, which was the most abundant substrate at one of the collecting sites. The abundance of these wood pellets in the digestive tract also indicates the functional importance of the jaws in viviparids. Wood pellets were mainly concentrated in the rectum, indicating apparently long retention times in the terminal part of the digestive tract, supporting its earlier stated importance for nutrient resorption (Chang, 1929). The large size of the pellets indicates an unselective deposit feeding strategy. The versatility between filter-feeding (ctenidium), scraping (radula) and non-selective deposit feeding (jaw + radula) may explain the success of some Cipangopaludina and Sinotaia species upon long-distance transport in comparison to other viviparids. More work is needed to determine whether $C$. japonica populations that were introduced in North America undergo seasonal diet shifts, and how food quantity and quality affect population density, growth and fecundity.

Fecundity. The number of females for which we examined reproductive output is small, but nevertheless provides an insight into the relationship between fecundity and body size. Differences in fecundity between males of different sizes is probably small in comparison to that between females of different sizes, which may explain different life expectancies for the sexes, and hence, given their indeterminate mode of growth, differences in size (Stańczykowska et al., 1971). Females of $C$. malleata attain larger adult sizes not by growing faster, but by living longer (on average 5 years instead of 4 for males, or up to $25 \%$ longer) in comparison to males, and in the additional reproductive period, they reach (on average) their highest reproductive success (Stańczykowska et al., 1971). All evidence suggests that females of $C$. japonica adopt a similar strategy to increase fecundity. Very similar observations were made on females of Campeloma crassula 
(Call, 1888), suggesting that our observations relate to a general life history strategy of viviparids.

Allometry. Substantial allometric variation is observed in $C$. japonica, as is the case in most viviparids, and given the linear relationship between PC1 and shell height (Fig. 15), we can conclude that shell shape parameters in $C$. japonica are determined early in ontogeny, i.e. in the sheltered, homogenous environment of the brood pouch, reducing the morphological variation induced by ecophenotypy. However, some allometric changes were observed in PC2, mainly for specimens with a shell height in the range of 2.7-4.5 $\mathrm{cm}$. These changes may relate to sexual maturation.

Sexual dimorphism. Marked anatomical dimorphism exists in $C$. japonica. Females usually have a larger body volume than males, because body volume relates directly to the accommodation of eggs and juveniles in the pallial oviduct, and hence fecundity. Regions within the visceral mass occupied by reproductive organs in females are occupied by connective tissue in males. The differences in body organization and tissue volume in similar-sized males and females of $C$.japonica also may have led to some sexual dimorphism in shell morphology, as described qualitatively above (Fig. 3). These differences were not entirely clear from our morphometric analyses (Fig. 14), which may have several causes. First, the number of sexed specimens that was analyzed was small; second, most of the morphological variation in our analyses related to allometric changes, which may have obscured more subtle differences in sexual dimorphism in shell shape. The first issue is probably the most critical, given that sexual dimorphism in viviparids is usually not sufficiently pronounced to be obvious from small samples (e.g. Call, 1888; Franz, 1928; Minton and Wang, 2011; Berezkina and Zotin, 2013). Although our observations indicate that sexual dimorphism exists in C. japonica, sexual selection appears to have been limited; females may prefer males that have similar body dimensions to themselves. Whatever the cause, male shell morphology has co-evolved with adaptations of the female body plan to maximize fecundity.

\section{Conclusions}

We studied systematics, anatomy and functional morphology of Cipangopaludina japonica to resolve misconceptions in the literature, e.g. as to how form and function relate to one another in this invasive species and by extension other bellamyines and viviparids. Overall the shell morphology and anatomy of C. japonica reflects that of other Bellamyinae, but within the subfamily notable differences exist in the radula, salivary glands, kidney, nerve ring, and reproductive organs (mainly the relative positions of the ovary and digestive gland in females). Hence, our study found several potentially phylogenetically informative differences at the subfamily level that have not been fully appreciated previously. The variation in reproductive anatomy within bellamyines is in line with earlier reported differences between viviparid subfamilies, but our work also indicates that the female reproductive system has been consistently misinterpreted in the past. More comparative work is required to obtain a full understanding of evolutionary changes between subfamilies and how they unfolded through time. In a number of features, Bellamyinae resemble other viviparid subfamilies (anatomy of mantle cavity organs, oesophagus), in others they compare well to other basal Architaenioglossa, primarily Ampullariidae (low spire; concentric opercula; tubular oviduct, rather than an open furrow or an oviduct in the pallial floor), and in still other features they resemble basal sorbeoconchans (epiathroid organization of the nerve ring). Our work highlights that more detailed anatomical comparisons across bellamyines are required to elucidate the systematics and evolution of the subfamily.

\section{Acknowledgements}

We thank two anonymous referees for constructive comments that improved the manuscript significantly; Elizabeth Diamond (USNM) for assistance with histology; Paul Greenhall and Kristen Mercer (USNM) for shipping and cataloguing specimens. BVB was supported by a Peter Buck Fellowship of the Smithsonian Institution, an Alexander von Humboldt Fellowship and a Fellowship of the Flanders Research Foundation.

\section{References}

Aldridge DW. 1983. Physiological ecology of freshwater prosobranchs. Pp. 329-358 in: Russell-Hunter WD, ed., The Mollusca - Ecology. London: Academic Press.

Anderson BE. 1966. Studies on the molluscan genus Campeloma Rafinesque, 1819. Sterkiana 23: 9-18.

Andrews EB. 1976. The fine structure of the heart of some prosobranch and pulmonate gastropods in relation to filtration. Journal of Molluscan Studies 42: 199-216. 
Andrews EB. 1979. Fine structure in relation to function in the excretory system of two species of Viviparus. Journal of Molluscan Studies 45: 186-206.

Andrews EB. 1988. Excretory Systems of Molluscs. Pp. 381448 in: Trueman ER, Clarke MR, eds, The Mollusca - Form and Function. London: Academic Press.

Andrews EB, Little C. 1972. Structure and function in the excretory systems of some terrestrial prosobranch snails (Cyclophoridae). Journal of Zoology 168: 395-422.

Ankel WE. 1925. Zur Befruchtungsfrage bei Viviparus viviparus L. nebst Bemerkungen über die erste Reifungsteilung des Eies. Senckenbergiana 7: 37-54.

Annandale N. 1920. Materials for a generic revision of the freshwater gastropod molluscs of the Indian Empire. Records of the Indian Museum 19: 107-115.

Annandale N, Rao HS. 1925. Further observations on the aquatic gastropods of the Inlé watershed. Records of the Indian Museum 27: 101-127.

Annandale N, Sewell RBS. 1921. The banded pond-snail of India (Vivipara bengalensis). Records of the Indian Museum 22: 215-299.

Auerbach L. 1896. Untersuchungen über die Spermatogenese von Paludina vivipara. Jenaische Zeitschrift für Naturwissenschaften 30: 405-554 (+ 402 plates).

Baker FC. 1928. The fresh water Mollusca of Wisconsin. Part 1. Gastropoda. Bulletin of the Wisconsin Geological and Natural History Survey 70.

Baudelot M. 1863. Recherches sur l'appareil générateur des mollusques gastéropodes. Annales des Sciences Naturelles (Zoologie), Paris 19: 135-222, 268-294.

Ben-Ami F, Hodgson AN. 2005. Ovoviviparity and the structure of the brood pouch in Melanoides tuberculata (Gastropoda: Prosobranchia: Thiaridae). Journal of Morphology 263: 322-329.

Berezkina GV, Zotin AA. 2013. Differences in the morphology of shells in males and females of the river snail (Viviparus viviparus, Gastropoda, Viviparidae). Zoologichesky Zhurnal 92: 875-881.

Berry AJ. 1974. Reproductive condition in two Malayan freshwater viviparid gastropods. Journal of Zoology 174: 357367.

Berthold T. 1991. Vergleichende anatomie, phylogenie und historische biogeographie der Ampullariidae. Abhandlungen des Naturwissenschaftlichen Vereins in Hamburg 29: 1-256.

Bouchet P, Rocroi J-P. 2005. Classification and nomenclator of gastropod families. Malacologia 47: 1-397.

Bouvier ME-L. 1887. Système nerveux, morphologie générale et classification des gastéropodes prosobranches. Annales des Sciences Naturelles, Zoologie 7: 1-510 (+ 518 plates).

Brandt RAM. 1974. The non-marine aquatic Mollusca of Thailand. Archiv für Molluskenkunde 105: 1-423.

Brown DS. 1994. Freshwater snails of Africa and their medical importance. London: Taylor and Francis.

Call RE. 1888. On the gross anatomy of Campeloma. American Naturalist 22: 491-497.

Chang M-C. 1929. The anatomy of the fresh water viviparous snails. Peking Society of Natural History Bulletin 3: 4559.

Clarke AH. 1978. The Asian apple snail, Cipangopaludina chinensis (Viviparidae) in Oneida Lake, New York. The Nautilus 92: 134.
Clench WJ. 1962. A catalogue of the Viviparidae of North America with notes on the distribution of Viviparus georgianus Lea. Occasional Papers on Mollusks 2: 261-287.

Clench WJ, Fuller SLH. 1965. The genus Viviparus (Viviparidae) in North America. Occasional Papers on Mollusks 2: 385-412.

Crabb ED. 1929. Egg laying and birth of young in three species of Viviparidae. The Nautilus 42: 125-129.

Du L-N, Yang J-X, Chen X-Y. 2011. A new species of Trochotaia (Caenogastropoda: Viviparidae) from Yunnan, China. Molluscan Research 31: 85-89.

Du LN, Yang JX, Rintelen Tv, Chen XY, Aldridge D. 2013. Molecular phylogenetic evidence that the Chinese viviparid genus Margarya (Gastropoda: Viviparidae) is polyphyletic. Chinese Science Bulletin 58: 2154-2162.

Dundee DS. 1974. Catalog of introduced mollusks of eastern North America (north of Mexico). Sterkiana 55: 1-36.

Falniowski A, Mazan K, Szarowska M. 1996. Tracing the viviparid evolution: radular characters (Gastropoda: Architaenioglossa: Viviparidae). Malakologische Abhandlungen 18: 43-52.

Fischer P. 1887. Manuel de conchyliologie et de paléontologie conchyliologique ou Histoire naturelle des mollusques vivants et fossiles. Paris: Librairie F. Savy.

Franz V. 1928. Paludinenstudien zur Frage der rezenten Paludina diluviana. Bibliotheca genetica 11: 1-144.

Fretter V, Graham A. 1994. British prosobranch molluscs their functional anatomy and ecology. Dorchester, UK: The Dorset Press.

Fukuda H, Haga T, Tatara Y. 2008. Niku-nuki: a useful method for anatomical and DNA studies on shell-bearing molluscs. Zoosypmposia 1: 15-38.

Germain L. 1920. Mollusques terrestres et fluviatiles. Voyage de M. Guy Babault dans l'Afrique Orientale Anglaise, 19121923: résultats scientifiques. Paris: Imprimerie F. Gaultier et A. Thébert.

Hannibal H. 1911. Further notes on Asiatic viviparas in California. Nautilus 25: 31-32.

Hannibal H. 1912. A synopsis of the recent and Tertiary freshwater Mollusca of the Californian province, based upon an ontogenetic classification. Proceedings of the Malacological Society of London 10: 112-211.

Haszprunar G. 1988. On the origin and evolution of major gastropod groups, with special reference to the Streptoneura. Journal of Molluscan Studies 54: 367-441.

Hayes KA, Cowie RH, Thiengo SC, Strong EE. 2012. Comparing apples with apples: clarifying the identities of two highly invasive Neotropical Ampullariidae (Caenogastropoda). Zoological Journal of the Linnean Society 166: 723-753.

Hirano T, Saito T, Chiba S. 2015. Phylogeny of freshwater viviparid snails in Japan. Journal of Molluscan Studies 81: 435441.

Humason GL. 1967. Animal tissue techniques. San Francisco, CA: W.H. Freeman.

Johnson SG, Bragg E. 1999. Age and polyphyletic origins of hybrid and spontaneous parthenogenetic Campeloma (Gastropoda: Viviparidae) from the Southeastern United States. Evolution 53: 1769-1781.

Jokinen EH. 1982. Cipangopaludina chinensis (Gastropoda: Viviparidae) in North America, review and update. The Nautilus 96: 89-95. 
Kobelt W. 1879. Fauna molluscorum extramarinorum Japoniae. Abhandlungen der Senckenbergischen Naturforschenden Gesellschaft 11: 1-171 (+ 123 plates).

Kuroda T. 1929. Notes on the nomenclature of the Japanese species of the genus Viviparus. The Venus 1: 98-102.

Leydig F. 1850. Über Paludina vivipara, Ein Beitrag zur näheren Kenntniss dieses Thieres in embryologischer, anatomischer und histologischer Beziehung. Zeitschrift für wissenschaftliche Zoologie 2: 125-197 (+123 plates).

Lu H-F, Du L-N, Li Z-Q, Chen X-Y, Yang J-X. 2014. Morphological analysis of the Chinese Cipangopaludina species (Gastropoda: Caenogastropoda: Viviparidae). Zoological Research 35: 510-527.

Mattox NT. 1938. Morphology of Campeloma rufum, a parthenogenetic snail. Journal of Morphology 62: 243-261.

Minton RL, Wang LL. 2011. Evidence of sexual shape dimorphism in Viviparus (Gastropoda: Viviparidae). Journal of Molluscan Studies 77: 315-317.

Moore JES. 1901. Further researches concerning the molluscs of the great African Lakes. Proceedings of the zoological society of London 2: 461-470.

Neumann G. 1928. Zur Kenntnis des Baues der Mantelorgane und des Mantelrandes von Paludina vivipara L. und Paludina ceylonica D. Jenaische Zeitschrift für Naturwissenschaften 68: 181-236.

Oksanen J, Blanchet FG, Kindt R, Legendre P, Minchin PR, O'Hara RB, Simpson GL, Solymos P, Henry M, Stevens H, Wagner H. 2013. Vegan: community ecology package: ordination, diversity and dissimilarities. R package. Version 2.08.

Opinion 573. 1959. Determination under the plenary powers of a lectotype for the nominal species Helix vivipara Linnaeus, 1758 , and addition to the Official List of the generic name Viviparus Montfort, 1810, and the family-group name Viviparidae Gray, 1847 (Class Gastropoda). Bulletin of Zoological Nomenclature 17: 117-131.

Ovando XMC, Cuezzo MG. 2012. Discovery of an established population of a non-native species of Viviparidae (Caenogastropoda) in Argentina. Molluscan Research 32: 121-131.

Perrier R. 1889. Récherches sur l'anatomie et l'histologie du rein des Gastéropodes Prosobranches. Annales des Sciences Naturelles, Zoologie 7: 61-311 (+ 313 plates).

Pilsbry HA. 1902. Revision of Japanese Viviparidae, with notes on Melania and Bithynia. Proceedings of the Academy of Natural Sciences of Philadelphia 54: 115-121.

Plinski M, Lawacz W, Stańczykowska A, Magnin E. 1978. Etude quantitative et qualitative de la nourriture des Viviparus malleatus (Reeve) (Gastropoda, Prosobranchia) dans deux lacs de la région de Montréal. Canadian Journal of Zoology 56: 272-279.

Ponder WF, Lindberg DR. 1997. Towards a phylogeny of gastropod molluscs: an analysis using morphological characters. Zoological Journal of the Linnean Society 119: 83-265.

Prashad B. 1928. Recent and fossil Viviparidae. A study in distribution, evolution and palaeogeography. Memoirs of the Indian Museum 8: 153-252.

R Development Core Team. 2013. R: A language and environment for statistical computing. Version 3.0.1. R Foundation for Statistical Computing. http://www.R-project.org.

Rao HS. 1925. On the comparative anatomy of Oriental Viviparidae. Records of the Indian Museum 27: 129-135.
Reeve LA. 1863. Monograph of the genus Paludina. In: Reeve LA, ed. Conchologia iconica, or Illustrations of the shells of molluscous animals. London: L. Reeve \& Co. 11 pls.

Ripley B. 2013. Bootstrap Functions (originally by Angelo Canty for S). R package. Version 1.3-9.

Rohlf FJ. 2010. TpsDig version 2.2.16. Department of Ecology and Evolution, State University of New York at Stony Brook.

Rohlf FJ. 2012. TpsUtil version 1.50. Department of Ecology and Evolution, State University of New York at Stony Brook.

Rohrbach F. 1937. Ökologische und morphologische Untersuchungen an Viviparus (Bellamya) capillatus Frauenfeld und Viviparus (Bellamya) unicolor Olivier, unter Berücksichtigung anderer tropischer Formen und im Hinblick auf phyletische Beziehungen. Archiv für Molluskenkunde 69: 177-218.

Salzburger W, Van Bocxlaer B, Cohen AS. 2014. Ecology and evolution of the African Great Lakes and their faunas. Annual Review of Ecology, Evolution and Systematics 45: 519545.

Savage AE. 1938. A comparison of the nervous system in normal and sinistral snails of the species Campeloma rufum. American Naturalist 72: 160-169.

Schultheiß R, Van Bocxlaer B, Riedel F, von Rintelen T, Albrecht C. 2014. Disjunct distributions of freshwater snails testify to a central role of the Congo system in shaping biogeographical patterns in Africa BMC Evolutionary Biology 14: e42.

Sengupta ME, Kristensen TK, Madsen H, Jørgensen A. 2009. Molecular phylogenetic investigations of the Viviparidae (Gastropoda: Caenogastropoda) in the lakes of the Rift Valley area of Africa. Molecular Phylogenetics and Evolution 52: 797-805.

Sheets HD. 2008. IMP: integrated morphometrics package: Department of Physics, Canisius College, Buffalo, N.Y.

Simone LRL. 2004. Comparative morphology and phylogeny of representatives of the superfamilies of architaenioglossans and the Annulariidae (Mollusca, Caenogastropoda). Arquivos do Museu Nacional, Rio de Janeiro 62: 387-504.

Simone LRL. 2011. Phylogeny of the Caenogastropoda (Mollusca), based on comparative morphology. Arquivos de Zoologia 42: 161-323.

Sivan N, Heller J, Van Damme D. 2006. Fossil Viviparidae (Mollusca: Gastropoda) of the Levant. Journal of Conchology 39: 207-219.

Smith DG. 2000. Notes on the taxonomy of introduced Bellamya (Gastropoda: Viviparidae) species in northeastern North America. The Nautilus 114: 31-37.

Soes DM, Majoor GD, Keulen SMA. 2011. Bellamya chinensis (Gray, 1834) (Gastropoda: Viviparidae), a new alien snail species for the European fauna. Aquatic Invasions 6: 97102.

Solomon CT, Olden JD, Johnson PTJ, Dillon RTJ, Vander Zanden MJ. 2010. Distribution and community-level effects of the Chinese mystery snail (Bellamya chinensis) in northern Wisconsin lakes. Biological Invasions 12: 1591-1605.

Speyer OWC. 1855. Zootomie der Paludina vivipara. Inaugural-dissertation, Marburg. Cassel: Fischer.

Stańczykowska A, Magnin E, Dumouchel A. 1971. Etude de trois populations de Viviparus malleatus (Reeve) (Gastropoda, Prosobranchia) de la région de Montréal. I. Croissance, fécondité, biomasse et production annuelle. Canadian Journal of Zoology 49: 1431-1441. 
Stańczykowska AM, Plinski M, Magnin E. 1972. Etude de trois populations de Viviparus malleatus (Reeve) (Gastropoda, Prosobranchia) de la région de Montréal. II. Etude qualitative et quantitative de la nourriture. Canadian Journal of Zoology 50: 1617-1624.

Starmühlner F. 1983. Results of the hydrobiological mission 1974 of the Zoological Institute of the University of Vienna. Part VIII: Contributions to the knowledge of the freshwatergastropods of the Indian Ocean Islands (Seychelles, Comores, Mascarene-Archipelagos). Annalen des Naturhistorischen Museums in Wien 84B: 127-249.

Starobogatov YI. 1992. Generic composition of the family Viviparidae (Gastropoda Pectinibranchia Vivipariformes). Transactions of the Zoological Institute, Academy of Sciences USSR 135: 26-32.

Strong EE. 2003. Refining molluscan characters: morphology, character coding and a phylogeny of the Caenogastropoda. Zoological Journal of the Linnean Society 137: 447-554.

Strong EE. 2011. More than a gut feeling: utility of midgut anatomy in phylogeny of the Cerithioidea (Mollusca: Caenogastropoda). Zoological Journal of the Linnean Society 162: 585-630.

Strong EE, Gargominy O, Ponder WF, Bouchet P. 2008. Global diversity of gastropods (Gastropoda; Mollusca) in freshwater. Hydrobiologia 595: 149-166.

Thiele J. 1929. Handbuch der systematischen Weichtierkunde. Jena: G. Fischer

Vail VA. 1977. Comparative reproductive anatomy of 3 viviparid gastropods. Malacologia 16: 519-540.
Vail VA. 1978. Seasonal reproductive patterns in 3 viviparid gastropods. Malacologia 17: 73-97.

Van Bocxlaer B, Hunt G. 2013. Morphological stasis in an ongoing gastropod radiation from Lake Malawi. Proceedings of the National Academy of Natural Sciences of the USA 110: 13892-13897.

Van Bocxlaer B, Schultheiß R. 2010. Comparison of morphometric techniques for shapes with few homologous landmarks based on machine-learning approaches to biological discrimination. Paleobiology 36: 497-515.

Van der Schalie H. 1936. Ovoviviparity among mollusks. Nautilus 50: 16-19.

Van der Schalie H. 1965. Observations on the sex of Campeloma (Gastropoda, Viviparidae). Occasional Papers of the Museum of Zoology, University of Michigan 611: 1-15.

von Erlanger R. 1891. Zur Entwicklung von Paludina vivipara. Morphologisches Jahrbuch 17: 337-376 (+ Pl 320-323; Part 331), 636-680 (+ Pl. 320-323; Part 332)

von Martens E. 1861. Die Japanesischen Binnenschnecken im Leidner Museum. Malakozoologische Blätter 7: 32-61.

Yen T-C. 1943. A preliminary revision of the recent species of Chinese Viviparidae. The Nautilus 56: 124-130.

Received: 2 June 2015

Revised and accepted: 9 December 2015

Published online: 15 June 2016

Editor: D. Huang 